\title{
Highly Effective Propane Dehydrogenation Using Ga-Rh Supported Catalytically Active Liquid Metal Solutions
}

Narayanan Raman, ${ }^{\mathrm{a}, \uparrow}$ Sven Maisel, ${ }^{\mathrm{b}, \uparrow}$ Mathias Grabau, ${ }^{\mathrm{c}}$ Nicola Taccardi, ${ }^{\mathrm{a}}$ Jonas Debuschewitz, ${ }^{\mathrm{a}}$ Moritz Wolf, ${ }^{a}$ Haiko Wittkämper, ${ }^{c}$ Tanja Bauer, ${ }^{d}$ Mingjian Wu, ${ }^{\text {e }}$ Marco Haumann, ${ }^{a}$ Christian Papp, ${ }^{c}$ Andreas Görling, ${ }^{b}$ Erdmann Spiecker, ${ }^{e}$ Jörg Libuda, ${ }^{d}$ Hans-Peter Steinrück, ${ }^{c}$ Peter Wasserscheid ${ }^{\mathrm{a}, \mathrm{f} *}$

a) Friedrich-Alexander-Universität Erlangen-Nürnberg (FAU), Lehrstuhl für Chemische Reaktionstechnik (CRT), Egerlandstr. 3, 91058 Erlangen, Germany, peter.wasserscheid@fau.de

b) Friedrich-Alexander-Universität Erlangen-Nürnberg (FAU), Lehrstuhl für Theoretische Chemie, Egerlandstr. 3, 91058 Erlangen, Germany

c) Friedrich-Alexander-Universität Erlangen-Nürnberg (FAU), Lehrstuhl für Physikalische Chemie II, Egerlandstr. 3, 91058 Erlangen, Germany

d) Friedrich-Alexander-Universität Erlangen-Nürnberg (FAU), Lehrstuhl für Katalytische Grenzflächenforschung, Egerlandstr. 3, 91058 Erlangen, Germany

e) Friedrich-Alexander-Universität Erlangen-Nürnberg (FAU), Lehrstuhl für Werkstoffwissenschaften, Mikro- und Nanostrukturforschung, Cauerstr. 6, 91058 Erlangen, Germany

f) Forschungszentrum Jülich, "Helmholtz-Institute Erlangen-Nürnberg for Renewable Energies" (IEK 11), Egerlandstr. 3, 91058 Erlangen, Germany

${ }^{\dagger}$ shared first authorship 
Supporting Information

\section{SUPPORTING INFORMATION}

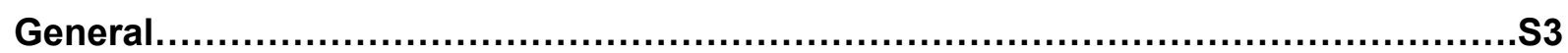

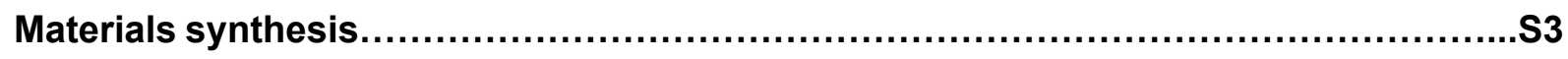

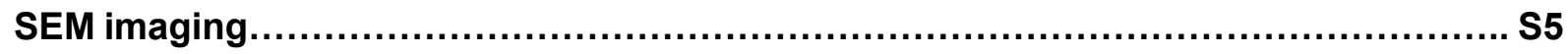

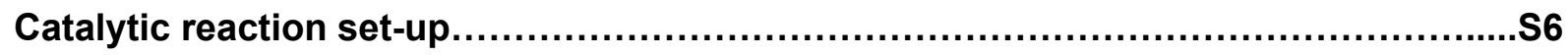

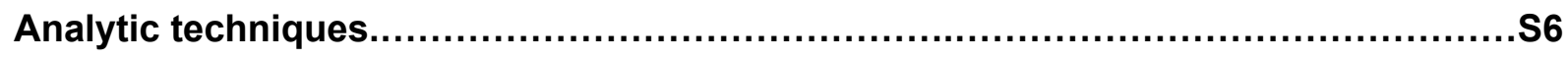

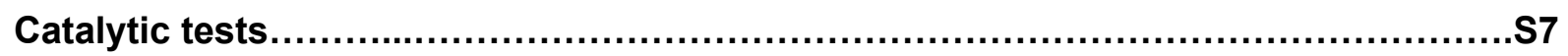

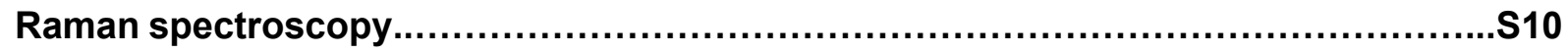

XPS measurement and analysis.......................................................... 11

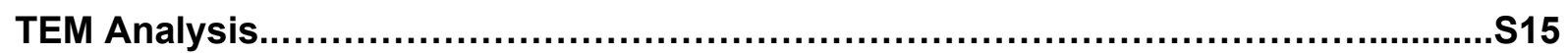

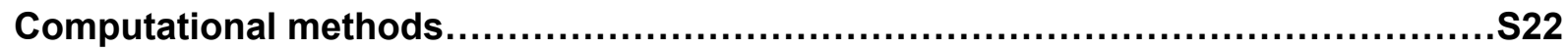

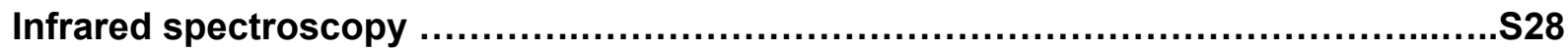




\section{GENERAL}

All reactions requiring protective atmosphere were carried out using standard Schlenck techniques. All reagents were commercial and used as received. The content of $\mathrm{Rh}$ and $\mathrm{Ga}$, and their ratio, was determined by inductively coupled plasma - atom emission spectroscopy (ICP-AES) using a Ciros CCD (Spectro Analytical Instruments $\mathrm{GmbH}$ ). The solid samples were digested with concentrated $\mathrm{HCl}: \mathrm{HNO}_{3}: \mathrm{HF}$ in a $3: 1: 1$ ratio in volume, using microwave heating up to $220^{\circ} \mathrm{C}$ for $40 \mathrm{~min}$ (CAUTION: HF solutions and vapors are extremely toxic, all manipulation has to be carried in a very efficient fume hood, wearing protective clothes, gloves, goggles). The instrument was calibrated for Rh (343.489 nm) and $\mathrm{Ga}(417.206 \mathrm{~nm})$ with standard solutions of the relevant elements prior to the measurements.

\section{MATERIALS SYNTHESIS}

\section{Preparation of $\left(\mathrm{Et}_{3} \underline{\underline{N}) \mathrm{GaH}_{3}}\right.$}

This compound was synthesized using the described procedure [1] using triethylammonium chloride (Sigma-Aldrich) instead of trimethylammonium chloride. The compound was not isolated and used as ethereal solution. The Ga content of this solution was determined as follow: $1 \mathrm{~mL}$ of ethereal solution was quenched in $10 \mathrm{~mL}$ of $\mathrm{HCl}(\sim 2 \mathrm{M})$ and the resulting mixture shortly boiled to evaporate the diethyl ether. The homogeneous solution was then diluted to $500 \mathrm{~mL}$ and the Ga content determined by ICPAES. Given the low stability of gallane complexes, the obtained $\left(\mathrm{Et}_{3} \mathrm{~N}\right) \mathrm{GaH}_{3}$ solution was used immediately after its preparation.

\section{Preparation of Ga decorated $\mathrm{Al}_{2} \underline{\mathrm{O}}_{3}$}

$100 \mathrm{~g}$ of $\mathrm{Al}_{2} \mathrm{O}_{3}$ (Sigma-Aldrich; grade: Brockmann I, activated, standard; particle size: 0.05-0.15 mm; BET surface area: $155 \mathrm{~m}^{2} / \mathrm{g}$; $\left.\mathrm{pH}: 7.0 \pm 0.5\right)$ were heated under vacuum $(1 \mathrm{mbar})$ at $300{ }^{\circ} \mathrm{C}$ overnight in a Schlenck flask. After cooling, the $\mathrm{Al}_{2} \mathrm{O}_{3}$ was suspended in $200 \mathrm{~mL}$ dry diethyl ether, under argon. The required amount of an ethereal solution of $\mathrm{Et}_{3} \mathrm{NGaH}_{3}$ was added to this suspension in order to obtain the desired theoretical Ga loading (ca. 6-7 \% w/w of Ga) with respect to the support. The ether was removed under vacuum at ca. $-30{ }^{\circ} \mathrm{C}$. After complete removal of diethyl ether, the flask was quickly (ca. $10{ }^{\circ} \mathrm{C}$ $/ \mathrm{min}$ ) heated up to $300{ }^{\circ} \mathrm{C}$ and held at this temperature until no gaseous products were observed any longer. Once the gallane decomposition terminated, the resulting grey solid was held at this temperature under vacuum (1 mbar) overnight and then cooled and stored under argon.

\section{Preparation of $R h / G$ a decorated material}

Typically, $5 \mathrm{~g}$ of Ga decorated $\mathrm{Al}_{2} \mathrm{O}_{3}$ were suspended in $50 \mathrm{~mL}$ of distilled water under vigorous stirring. This suspension was heated at $50{ }^{\circ} \mathrm{C}$ and a stock solution of $\mathrm{RhCl}_{3} \cdot 3 \mathrm{H}_{2} \mathrm{O}$ (with a nominal $\mathrm{Rh}$ concentration of $1 \mathrm{mg} / \mathrm{ml})$ in distilled water was added. Given the Ga load $(\% \mathrm{w} / \mathrm{w})$ of the material, the added amount of stock solution was adjusted to obtain the desired final $\mathrm{Ga} / \mathrm{Rh}$ ratio, accounting for the loss of $\mathrm{Ga}$ due to the redox reaction between the latter and the $\mathrm{Rh}^{3+}$ cation (see Supplementary Figure 1). The resulting suspension was held under stirring for $15 \mathrm{~min}$. Then, the solution was filtered and the material was thoroughly washed with distilled water $(500 \mathrm{ml})$. The resulting solid was dried in an oven at $130{ }^{\circ} \mathrm{C}$, overnight. The obtained materials, their $\mathrm{Ga}$ and $\mathrm{Rh}$ loading, as well as the respective $\mathrm{Ga} / \mathrm{Rh}$ ratio are listed in Supplementary Table 1. 


$$
\begin{gathered}
\mathrm{Rh}^{3+}+\mathrm{Ga}^{0} \longrightarrow \mathrm{Rh}^{0}+\mathrm{Ga}^{3+} \\
\mathrm{Ga} / \mathrm{Rh}=\frac{\left[\left(\mathrm{m}_{\mathrm{Ga}} / 69.723\right)-\left(\mathrm{m}_{\mathrm{Rh}} / 101.9055\right)\right]}{\left(\mathrm{m}_{\mathrm{Rh}} / 101.9055\right)}
\end{gathered}
$$

Figure S1: Galvanic displacement for the adjustment of the Rh-content in the SCALMS catalyst. The final $\mathrm{Ga} / \mathrm{Rh}$ ratio is obtained by the mass of $\mathrm{Ga}$ on the support $\left(\mathrm{m}_{\mathrm{Ga}}\right)$ and the mass of added $\mathrm{Rh}\left(\mathrm{m}_{\mathrm{Rh}}\right)$, once accounted for the galvanic displacement reaction.

Table S1. Compositions of the different catalysts used in this study

\begin{tabular}{|c|c|c|c|}
\hline catalyst & Ga \% $_{\mathbf{w} / \mathbf{w}}$ & $\mathbf{R h} \mathbf{\%}_{\mathbf{w} / \mathbf{w}}$ & $\mathbf{G a} / \mathbf{R h}$ \\
\hline Rh & 0 & 0.19 & 0 \\
\hline GaRh25 & 5.65 & 0.33 & 25 \\
\hline GaRh34 & 5.90 & 0.26 & 34 \\
\hline GaRh82 & 5.90 & 0.11 & 82 \\
\hline GaRh89 & 6.06 & 0.10 & 89 \\
\hline GaRh125 & 5.94 & 0.07 & 125 \\
\hline Ga & 6.40 & 0 & - \\
\hline All the values were determined with ICP-AES (see above) and are accurate within an error of $\pm 3 \%$ \\
\hline
\end{tabular}

\section{$\underline{\text { Preparation of } R \mathrm{Rh} / \mathrm{Al}_{2}} \underline{\mathrm{O}}_{3} \underline{\text { catalyst }}$}

A $100 \mathrm{~mL}$ flask was charged with 5.01 of $\mathrm{Al}_{2} \mathrm{O}_{3}$ and ca. $20 \mathrm{~mL}$ of distilled water. $12.5 \mathrm{~mL}$ of a solution $\mathrm{Rh}\left(\mathrm{NO}_{3}\right)_{3}$ (with a nominal $\mathrm{Rh}$ concentration of $1 \mathrm{mg} / \mathrm{L}$ ) were added. The water was evaporated under vacuum $(1 \mathrm{mbar})$ at $50^{\circ} \mathrm{C}$. The resulting off-white powder was calcined for 12 $\mathrm{h}$ at $450^{\circ} \mathrm{C}$. The obtained off-white material was transferred to the reduction reactor and reduced with a stream of pure $\mathrm{H}_{2}(60 \mathrm{~mL} / \mathrm{min})$, at $300{ }^{\circ} \mathrm{C}$ for $3 \mathrm{~h}$. The resulting grey powder was analyzed by means of ICP-AES, giving a Rh content of $0.19 \%$ w/w.

\section{$\underline{\text { PVD preparation of bimetallic model samples on TEM grids }}$}

Rh (wire, $1 \mathrm{~mm}$ diameter, MatecK, $99.9 \%$ ) and Ga (in a pyrolytic boron nitride crucible, Alfa Aesar, $99.99999 \%)$ were evaporated using a Focus EFM 3T evaporator. A quartz crystal microbalance was used to assure constant deposition rates. The base pressure of the used UHV system lies within the lower $10^{-10}$ mbar range. During deposition pressures in the low (Rh) and high $(\mathrm{Ga}) 10^{-9}$ mbar range are observed. 


\section{Supporting Information}

\section{SEM IMAGING}

Scanning Electron Microscopy (SEM) analysis was carried out with a Zeiss Evo 40 instrument using voltages between 15 and $25 \mathrm{kV}$ and beam currents between 50 and $2000 \mathrm{pA}$. The EDX intensity maps shown as superposition in Supplementary Figure 2d) show the AlOx particle imaged in Supplementary Figure 2a) at similar magnification. The particles were deposited directly on a conductive sticky carbon pad (Plano GmbH).

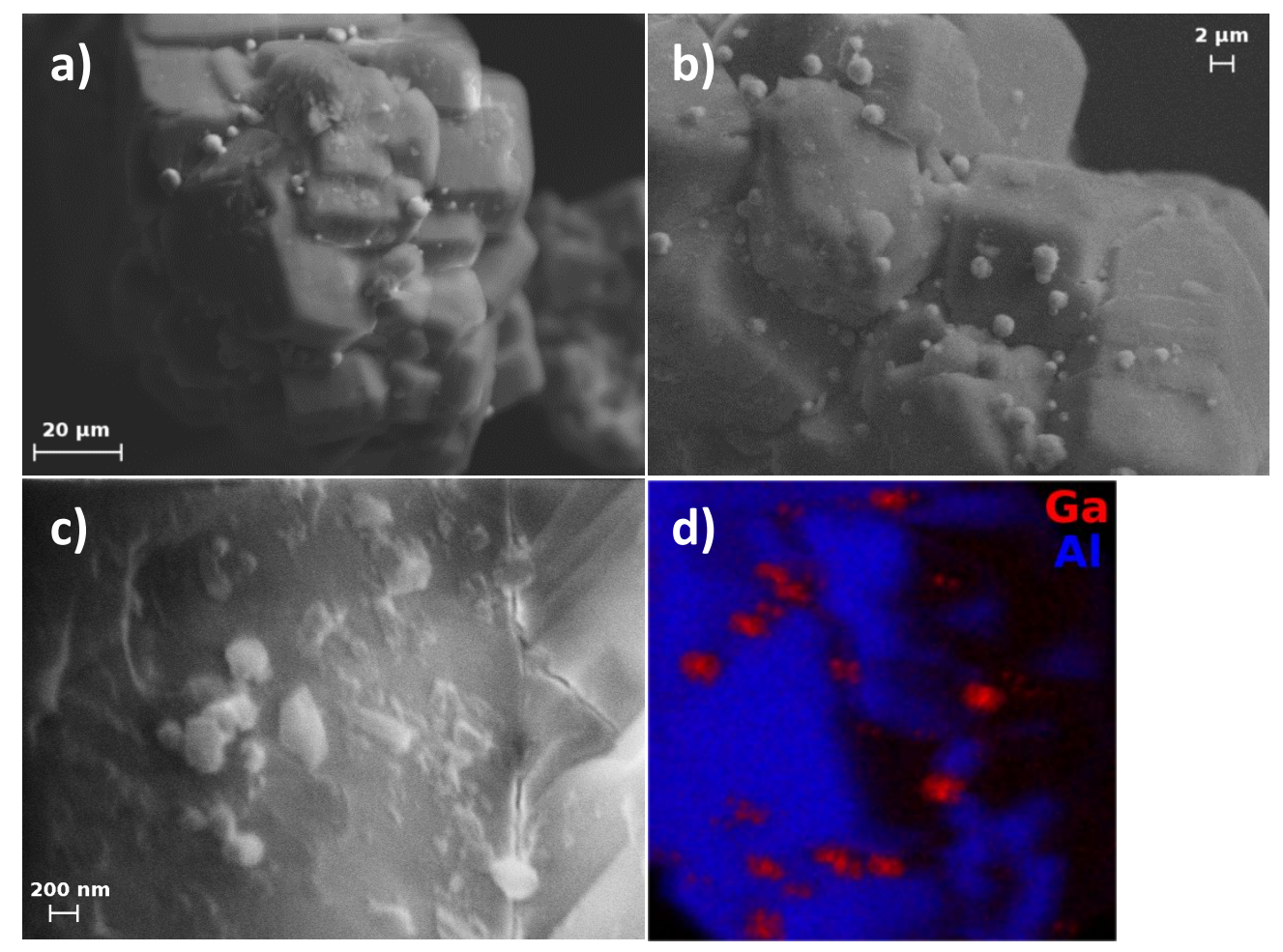

Figure S2: a-c) SEM imaging of the $\mathrm{Ga}_{125} \mathrm{Rh}$ SCALMS and d) EDX intensity maps of 2a.

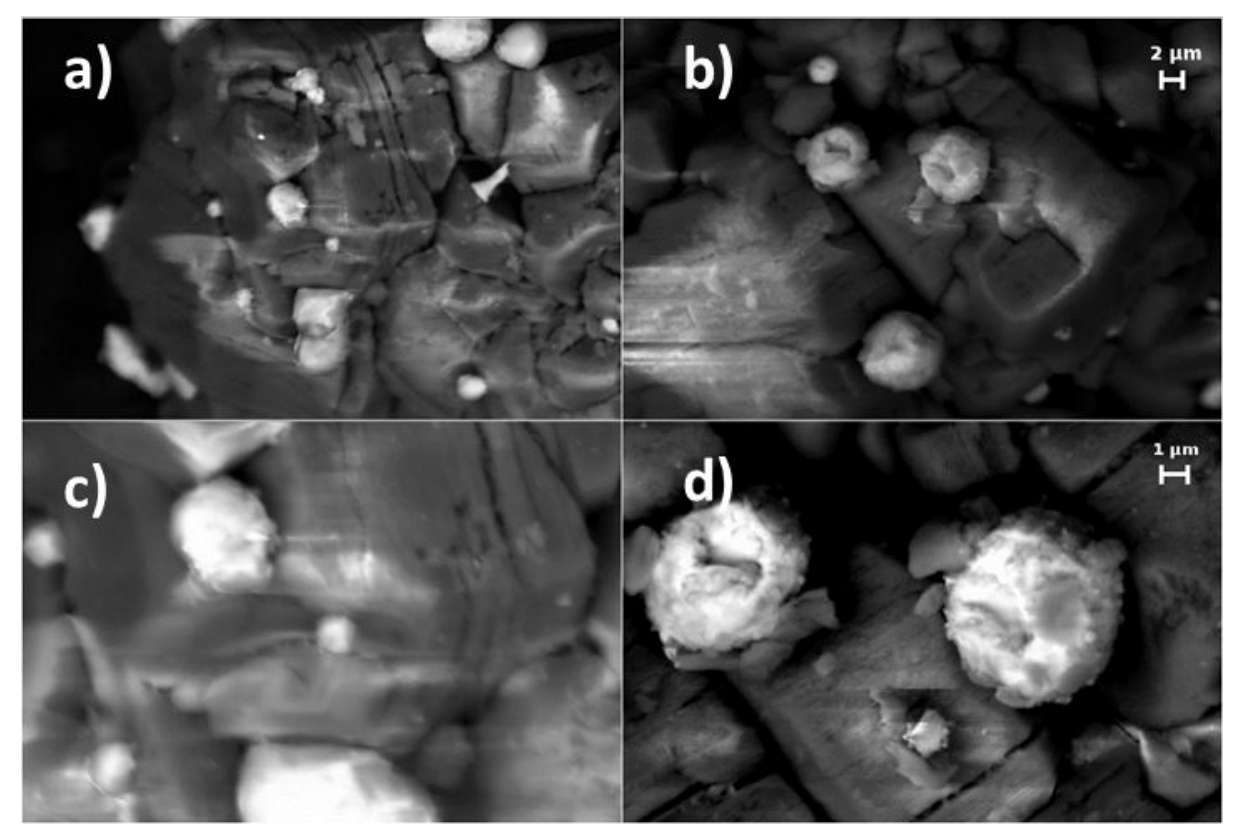

Figure S3: SEM imaging of the $\mathrm{Ga}_{25} \mathrm{Rh}$ SCALMS before (a and c) and after (b and d) the catalytic reaction 


\section{CATALYTIC REACTION SET-UP}

The catalysts were used as prepared according to the above procedure. They were not reduced prior to catalytic testing. The catalytic tests were carried out in a continuous flow laboratory rig at atmospheric pressure. The flowsheet of the rig is depicted in Figure S4. A defined catalyst mass of $1.2 \mathrm{~g}$ was placed into the fixed-bed reactor. The reactor was heated to the set point at $10^{\circ} \mathrm{C} / \mathrm{min}$ and after a stabilization time of $15 \mathrm{~min}$, the reaction was started by supplying $8.9 \mathrm{~mL}_{\mathrm{N}} \mathrm{min}^{-1}$ propane (Linde, purity 2.5) as feed gas diluted with $89 \mathrm{~mL}_{\mathrm{N}} \mathrm{min}^{-1}$ helium (Linde, purity 4.6), respectively. This resulted in a gas hourly space velocity (GHSV) of $4900 \mathrm{ml}_{\text {gas }} \mathrm{ml}_{\text {Cat. bed }}{ }^{-1} \mathrm{~h}^{-1}$ and in a residence time $\tau$ of $0.7 \mathrm{~s}$ (at standard conditions). The gases were dosed by mass flow controllers (MFC, Bronckhorst). All reactor tubes and pipes were held at $100{ }^{\circ} \mathrm{C}$ by using heating tapes and fiberglass tape insolation. The Quartz fixed-bed reactor was heated by a tubular split furnace. All other parts which were in contact with the reactants were made of stainless steel 1.4571 .

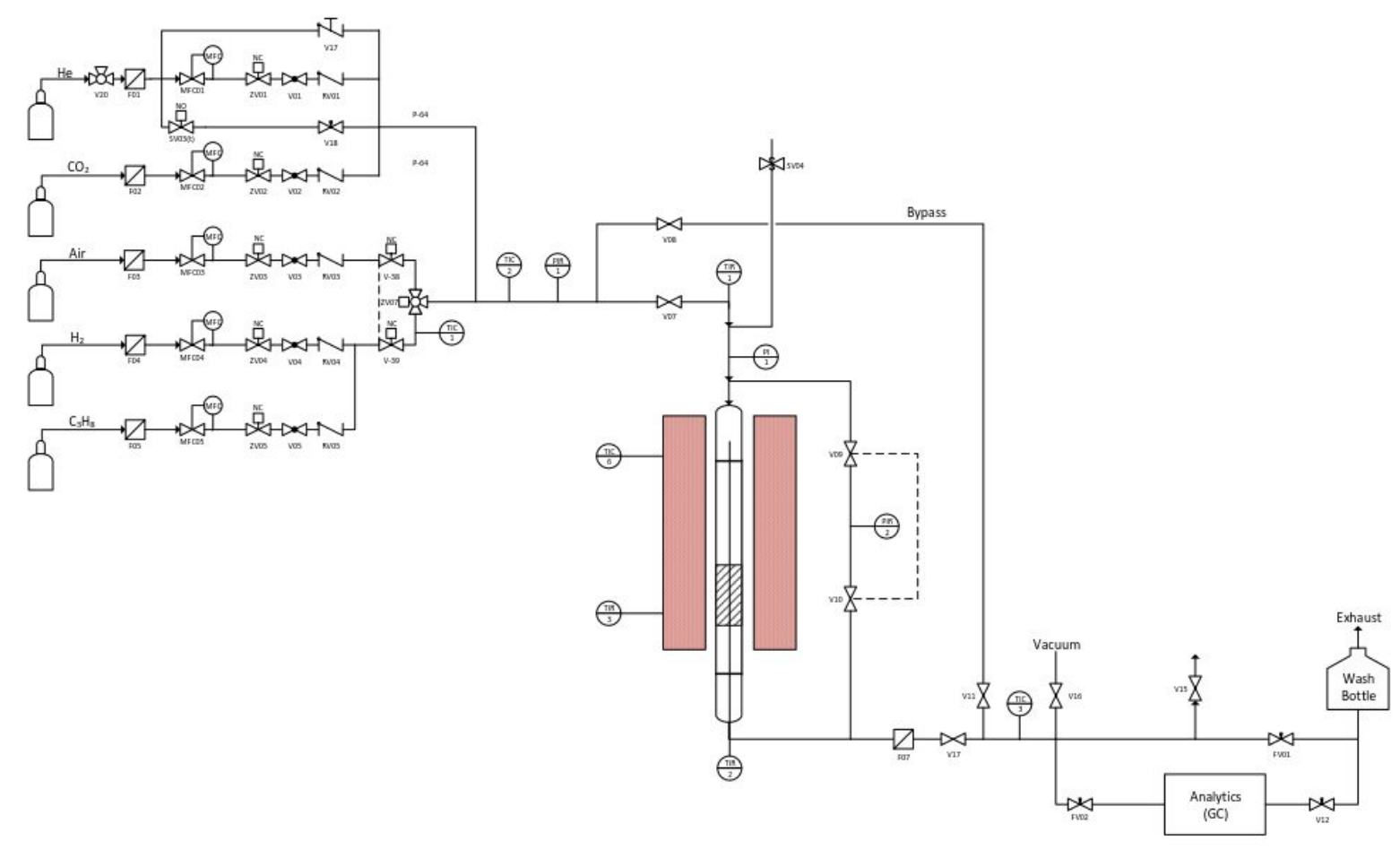

Figure S4: Flowsheet of the continuous-flow experimental laboratory rig applied within this work for the dehydrogenation of propane.

\section{ANALYTIC TECHNIQUES}

The product stream was analyzed by online GC using a Bruker 456 GC equipped with a GC-Gaspro column ( $30 \mathrm{~m} \times 0.320 \mathrm{~mm})$ and a flame ionization detector (FID). Mole fractions $\mathrm{x}$ are calculated from peak areas and calibration factors determined for every substance. The conversion of propane $\left(\mathrm{X}_{\text {propane }}\right)$, Productivity and the selectivity to propene $\left(\mathrm{S}_{\text {Propylene }}\right)$ are calculated as follows:

$X_{n-\text { propane }}=\frac{x_{\text {propane }, 0}-x_{\text {propane }}}{x_{\text {propane }, 0}} \cdot 100 \%$

Productivity $=\frac{\dot{g}_{\text {propane }, 0} \cdot S_{\text {propylene }} \cdot X_{\text {propane }}}{g_{R h}}$

$S_{\text {propylene }}=\frac{x_{\text {propylene }}}{x_{\text {propylene }}+x_{\text {methane }}+x_{\text {ethane }}+x_{\text {ethene }}} \cdot 100 \%$ 
The productivities values were calculated accounting for the mass of $\mathrm{Rh}$ in the catalytic reactor.

\section{CATALYTIC TESTS}

\section{Blind activity test with empty bed}

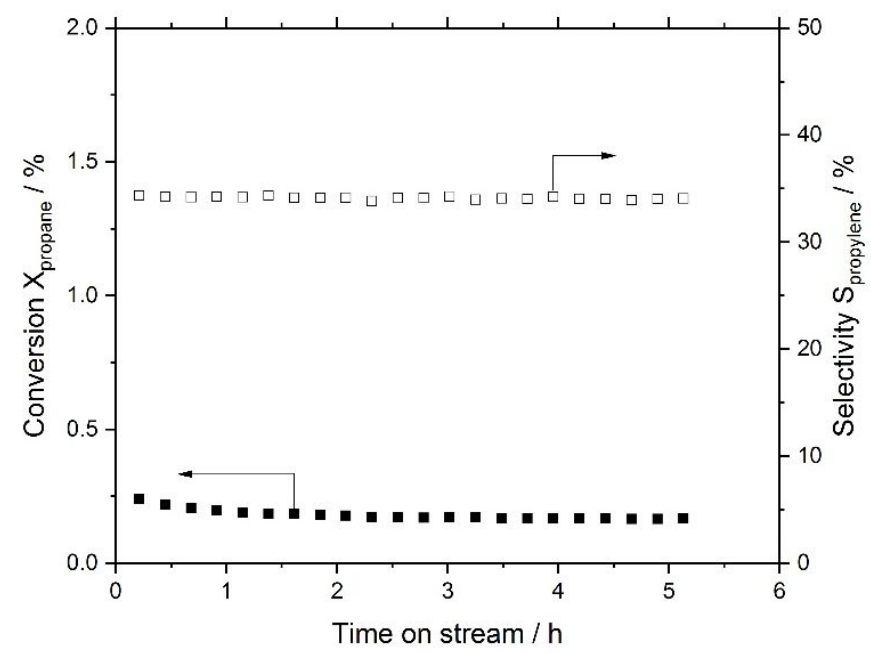

Figure S5: Selectivity and conversion of different of the empty quartz reactor in propane dehydrogenation at $550{ }^{\circ} \mathrm{C}$ and 1.2 bar. He flow $89 \mathrm{~mL}_{\mathrm{N}} \mathrm{min}^{-1}, \mathrm{C}_{3} \mathrm{H}_{8}$ flow $8.9 \mathrm{~mL}_{\mathrm{N}} \mathrm{min}^{-1}$, GHSV $4900 \mathrm{~h}^{-1}$.

\section{Dehydrogenation of helium diluted propane feed with RhGa- SCALMS at $450^{\circ} \mathrm{C}$}
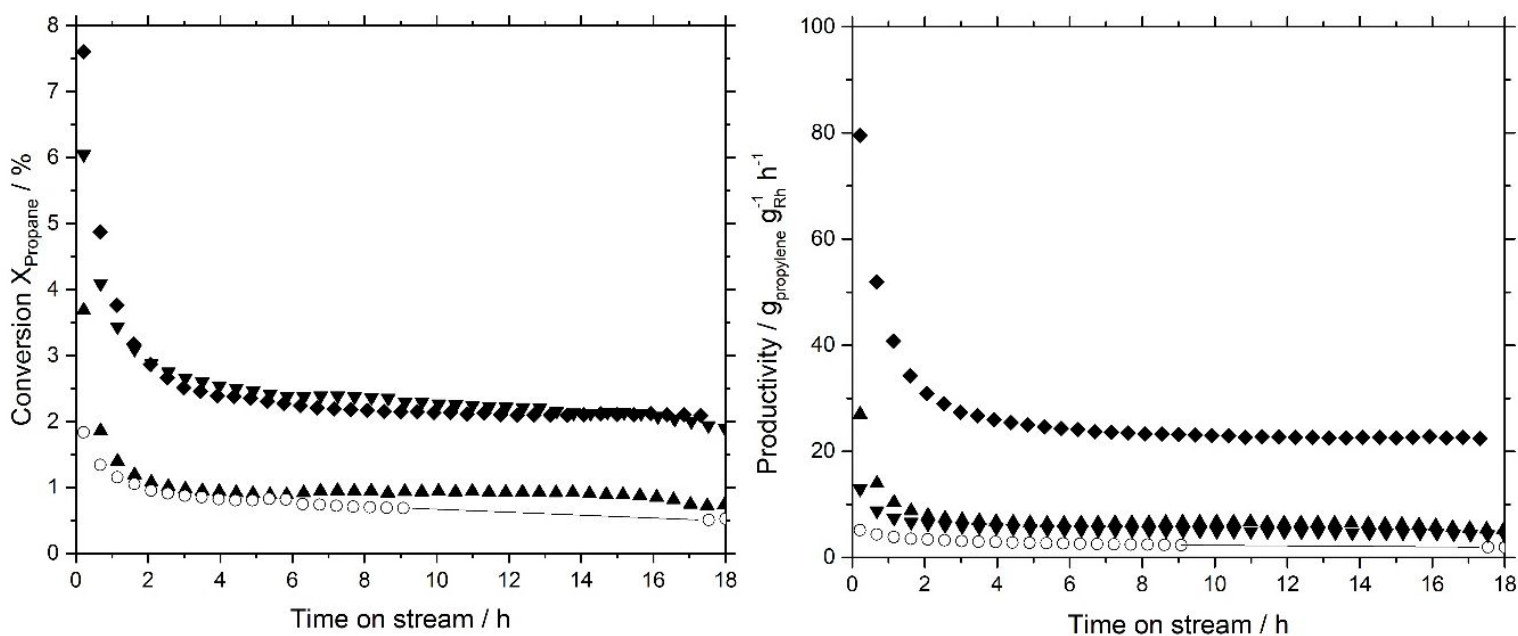

Figure S6: Conversion (left) and Rh based productivity (right) of different Ga/Rh-SCALMS in propane dehydrogenation at $450^{\circ} \mathrm{C}$ and 1.2 bar. Molar ratios of Ga:Rh are 0 (open circles), 25 (downward-pointing triangles), 89 (upward-pointing triangles) and 125 (diamonds). Reaction conditions: $1.2 \mathrm{~g}$ catalyst $\left(\mathrm{Rh} / \mathrm{Al}_{2} \mathrm{O}_{3}: 0.19 \mathrm{wt} \% \mathrm{Rh} ; \mathrm{Rh}_{1}-\mathrm{Ga}_{25}: 0.33 \% \mathrm{Rh}, 5.65 \% \mathrm{Ga} ; \mathrm{Rh}_{1}-\mathrm{Ga}_{89}: 0.10\right.$ \%Rh, $6.06 \% \mathrm{Ga} ; \mathrm{Rh}_{1}-\mathrm{Ga}_{125}: 0.07 \% \mathrm{Rh}, 5.94 \% \mathrm{Ga}$ ), He flow $89 \mathrm{~mL}_{\mathrm{N}} \mathrm{min}^{-1}, \mathrm{C}_{3} \mathrm{H}_{8}$ flow $8.9 \mathrm{~mL}_{\mathrm{N}} \mathrm{min}^{-1}$, GHSV $4900 \mathrm{~h}^{-1}$. 


\section{Dehydrogenation of helium diluted propane feed with RhGa-SCALMS at $480^{\circ} \mathrm{C}$}
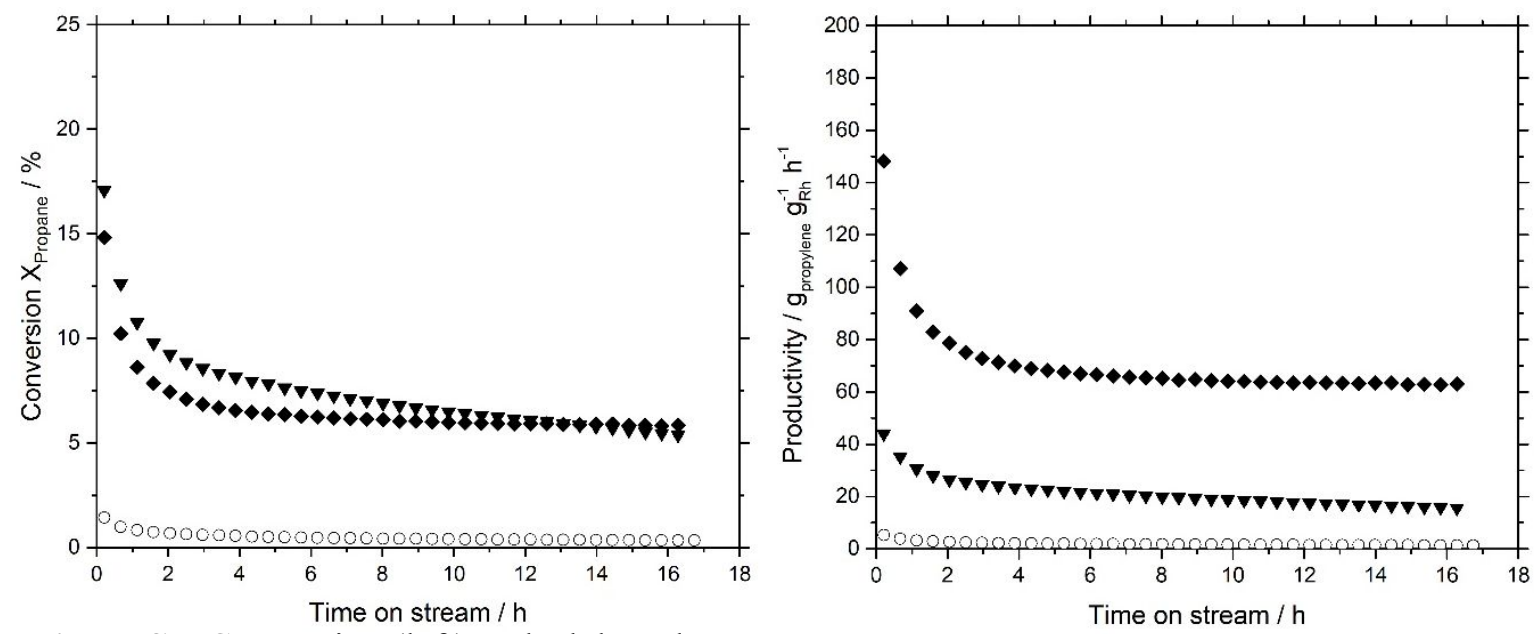

Figure S7: Conversion (left) and Rh based productivity (right) of different $\mathrm{Ga} / \mathrm{Rh}$-SCALMS in propane dehydrogenation at $480{ }^{\circ} \mathrm{C}$ and 1.2 bar. Molar ratios of Ga:Rh are 0 (open circles), 34 (downward-pointing triangles) and 125 (diamonds). Reaction conditions: $1.2 \mathrm{~g}$ catalyst $\left(\mathrm{Rh} / \mathrm{Al}_{2} \mathrm{O}_{3}: 0.19 \mathrm{wt} . \% \mathrm{Rh} ; \mathrm{Rh}_{1}-\mathrm{Ga}_{34}: 0.33 \% \mathrm{Rh}, 5.65 \% \mathrm{Ga} ; \mathrm{Rh}_{1}\right.$ $\mathrm{Ga}_{125}: 0.07 \% \mathrm{Rh}, 5.94 \% \mathrm{Ga}$ ), He flow $89 \mathrm{~mL}_{\mathrm{N}} \min ^{-1}, \mathrm{C}_{3} \mathrm{H}_{8}$ flow $8.9 \mathrm{~mL}_{\mathrm{N}} \mathrm{min}^{-1}$, GHSV $4900 \mathrm{~h}^{-1}$.

\section{Dehydrogenation of helium diluted propane feed with RhGa-SCALMS at $500^{\circ} \mathrm{C}$}
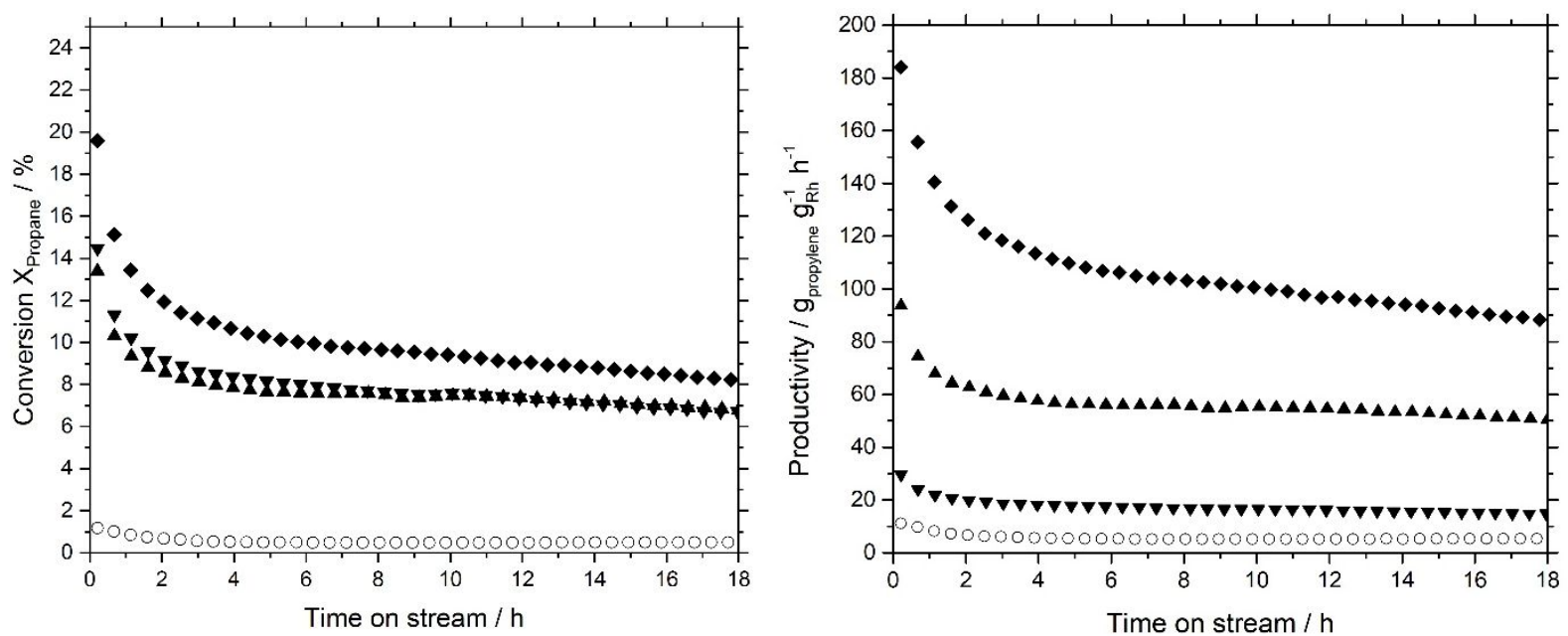

Figure S8: Conversion (left) and $\mathrm{Rh}$ based productivity (right) of different $\mathrm{Ga} / \mathrm{Rh}-\mathrm{SCALMS}$ in propane dehydrogenation at $500{ }^{\circ} \mathrm{C}$ and $1.2 \mathrm{bar}$. Molar ratios of $\mathrm{Ga}: \mathrm{Rh}$ are 0 (open circles), 25 (downward-pointing triangles), 88 (upward-pointing triangles) and 125 (diamonds). Reaction conditions: $1.2 \mathrm{~g}$ catalyst $\left(\mathrm{Rh} / \mathrm{Al}_{2} \mathrm{O}_{3}: 0.19 \mathrm{wt} \% \% \mathrm{Rh} ; \mathrm{Rh}_{1}-\mathrm{Ga}_{25}\right.$ : $0.33 \% \mathrm{Rh}, 5.65 \% \mathrm{Ga} ; \mathrm{Rh}_{1}-\mathrm{Ga}_{89}: 0.10 \% \mathrm{Rh}, 6.06 \% \mathrm{Ga} ; \mathrm{Rh}_{1}-\mathrm{Ga}_{125}: 0.07 \% \mathrm{Rh}, 5.94 \% \mathrm{Ga}$ ), He flow 89 $\mathrm{mL}_{\mathrm{N}} \min ^{-1}, \mathrm{C}_{3} \mathrm{H}_{8}$ flow $8.9 \mathrm{~mL}_{\mathrm{N}} \mathrm{min}^{-1}$, GHSV $4900 \mathrm{~h}^{-1}$. 


\section{Propene selectivity of RhGa- SCALMS catalysts at various temperatures during propane dehydrogenation}

With the exception of pure $\mathrm{Rh} / \mathrm{Al}_{2} \mathrm{O}_{3}$ catalyst, all catalysts showed nearly constant selectivity for propene over the entire duration of experiment. The observed selectivity values for the all catalysts across the temperature range is summarized in the table $\mathrm{S} 2$ below.

Table S2: Selectivities of RhGa- SCALMS catalysts at various temperatures during propane dehydrogenation over $15 \mathrm{~h}$ TOS

\begin{tabular}{llr}
\hline Temperature $/{ }^{\circ} \mathrm{C}$ & Ga:Rh ratio/ & Selectivity, $S_{\text {propene }} / \%$ \\
\hline $450{ }^{\circ} \mathrm{C}$ & & $92 \pm 2$ \\
& $\mathrm{Ga} / \mathrm{Rh}: 25$ & $91 \pm 4$ \\
& $\mathrm{Ga} / \mathrm{Rh}: 89$ & $95 \pm 2$ \\
& $\mathrm{Ga} / \mathrm{Rh}: 125$ & $79 \pm 12$ \\
& $\mathrm{Rh} / \mathrm{Alox}: 0$ & \\
& & $91 \pm 5$ \\
$480^{\circ} \mathrm{C}$ & $\mathrm{Ga} / \mathrm{Rh}: 34$ & $93 \pm 3$ \\
& $\mathrm{Ga} / \mathrm{Rh}: 125$ & $88 \pm 4$ \\
& $\mathrm{Rh} / \mathrm{Alox}$ & \\
& & $89 \pm 4$ \\
$500^{\circ} \mathrm{C}$ & $\mathrm{Ga} / \mathrm{Rh}: 25$ & $92 \pm 3$ \\
& $\mathrm{Ga} / \mathrm{Rh}: 89$ & $90 \pm 6$ \\
& $\mathrm{Ga} / \mathrm{Rh}: 125$ & $81 \pm 6$ \\
& $\mathrm{Rh} / \mathrm{Alox}$ & $88 \pm 5$ \\
& & $89 \pm 4$ \\
$550^{\circ} \mathrm{C}$ & $\mathrm{Ga} / \mathrm{Rh}: 34$ & $87 \pm 7$ \\
& $\mathrm{Ga} / \mathrm{Rh}: 82$ & $71 \pm 20$ \\
\hline $\mathrm{Ga} / \mathrm{Rh}: 125$ & $\mathrm{Rh} / \mathrm{Alox}$ &
\end{tabular}

\section{Dehydrogenation of propane by $\mathrm{Ga}_{1} \mathrm{Al}_{2} \underline{O}_{3}$ catalyst - Base line tests}
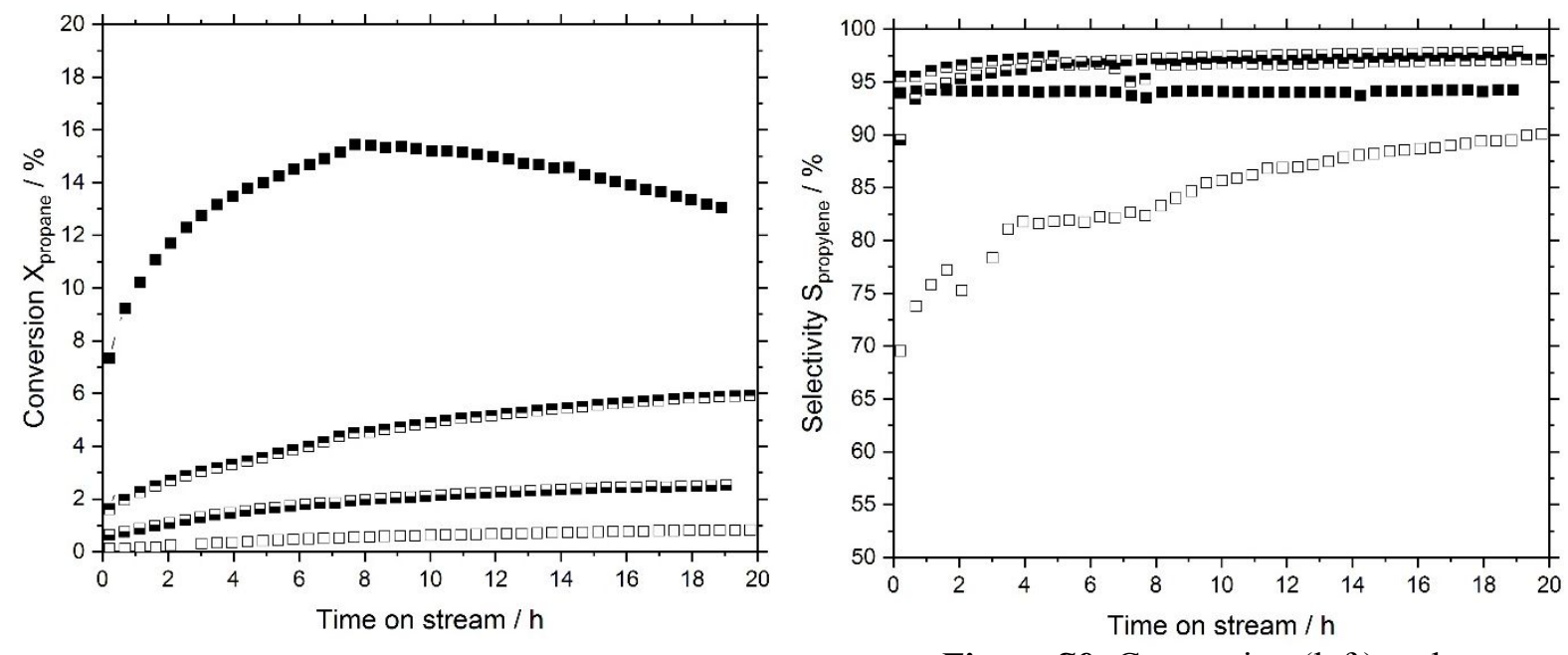

Figure S9: Conversion (left) and

Selectivity(right) of $\mathrm{Ga}^{-} \mathrm{Al}_{2} \mathrm{O}_{3}$ in propane dehydrogenation at $450{ }^{\circ} \mathrm{C}$ (open square), $480^{\circ} \mathrm{C}$ (bottom 
half-filled square) $500^{\circ} \mathrm{C}$ (top half-filled square) and $550^{\circ} \mathrm{C}$ (filled square) at 1.2 bar. Reaction conditions: $1.2 \mathrm{~g}$ catalyst $\left(\mathrm{Ga} / \mathrm{Al}_{2} \mathrm{O}_{3}: 6.4 \mathrm{wt} . \% \mathrm{Ga}\right)$, He flow $89 \mathrm{~mL}_{\mathrm{N}} \mathrm{min}^{-1}, \mathrm{C}_{3} \mathrm{H}_{8}$ flow $8.9 \mathrm{~mL}_{\mathrm{N}} \mathrm{min}^{-1}$, GHSV $4900 \mathrm{~h}^{-1}$.

\section{RAMAN SPECTROSCOPY}

Raman spectroscopy of SCALMS after catalytic application was conducted using an AvaRaman-PRB-532 (Avantes) probe and an AvaRaman-532HERO-EVO (Avantes) system. The system consists of a $532 \mathrm{~nm}$ (green) solid state laser (Cobolt) and an AvaSpec-HERO (Avantes) spectrometer with a grating set of 1200 lines $\mathrm{mm}^{-1}$ (HSC1200-0.75). The spectrometer was equipped with a $50 \mu \mathrm{m}$ slit and the detected wavelength range was 534-696 $\mathrm{nm}$. The spectra were collected in 20 repetitions at $15 \mathrm{~mW}$ laser power with an exposure time of $5 \mathrm{~s}$.

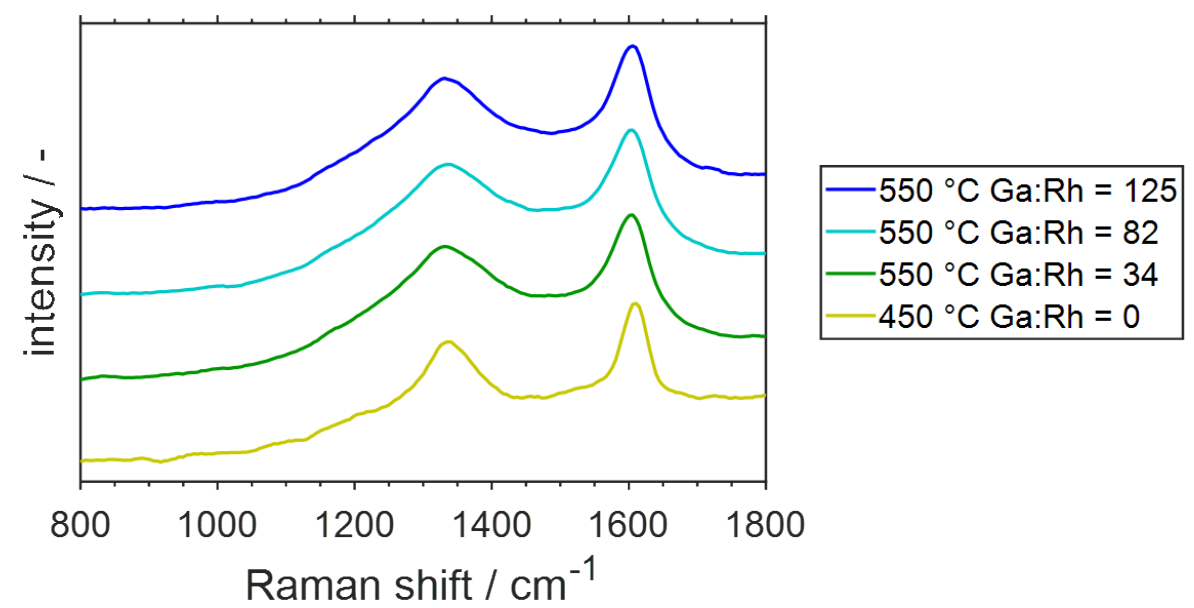

Figure S10: Raman spectra of spent SCALMS after propane dehydrogenation at $550{ }^{\circ} \mathrm{C}$, as well as the spectra of a spent $\mathrm{Rh} / \mathrm{Al}_{2} \mathrm{O}_{3}$ catalyst after dehydrogenation at $450{ }^{\circ} \mathrm{C}$.

Table S3: Characteristic values of the D and G band in the Raman spectra of spent Ga-Rh SCALMS after propane dehydrogenation at $550{ }^{\circ} \mathrm{C}$ and a $\mathrm{Rh} / \mathrm{Al} 2 \mathrm{O} 3$ reference sample after dehydrogenation at $450{ }^{\circ} \mathrm{C}$.

\begin{tabular}{l|l|l|l|l|l|l|} 
catalyst & PDH temperature & $\boldsymbol{I}_{\mathbf{G}} \boldsymbol{I}_{\mathbf{D}}$ & \multicolumn{2}{|c|}{$\mathbf{D}$ band $/ \mathbf{~ c m}^{-\mathbf{1}}$} & $\mathbf{G}$ band $/ \mathbf{~ c m}^{-\mathbf{1}}$ \\
\cline { 4 - 8 } & & & FWHM & Position & FWHM & Position \\
\hline $\mathbf{G a} / \mathbf{R h}=\mathbf{1 2 5}$ & 550 & 1.188 & 203.5 & 1338 & 67.2 & 1601 \\
\hline $\mathbf{G a} / \mathbf{R h}=\mathbf{8 2}$ & 550 & 1.146 & 214.6 & 1340 & 72.3 & 1599 \\
\hline $\mathbf{G a} / \mathbf{R h}=\mathbf{3 4}$ & 550 & 1.148 & 203.8 & 1338 & 68.7 & 1599 \\
\hline $\mathbf{G a} / \mathbf{R h}=\mathbf{0}$ & 450 & 1.346 & 136.5 & 1337 & 46.1 & 1607
\end{tabular}




\section{XPS MEASUREMENT AND ANALYSIS}

Different catalyst samples of alumina-supported $\mathrm{Ga} / \mathrm{Rh}$ catalysts with a Ga loading of $6.0 \mathrm{wt} . \%$ and Ga:Rh ratios of 16:1, 25:1, 58:1, 88:1 and 125:1 were examined using X-ray photoelectron spectroscopy (XPS). In addition, bimetallic Ga-Rh model systems with Ga:Rh ratios of 49:1, 82:1 and 166:1 (2.0, 1.2 and 0.6 at.\% Rh) were studied. All spectra were collected in ultra-high vacuum using a non-monochromatized $\mathrm{Al} \mathrm{K}_{\mathrm{a}} \mathrm{X}$-ray source, at normal electron emission. $\mathrm{A}$ detailed description of the XPS setup can be found elsewhere[2].

The preparation of all catalyst samples for the XPS measurements was done at room temperature and in air. The powder samples were attached to the $\mathrm{W}$ foil using a $\mathrm{H}_{2} \mathrm{O}$-based $\mathrm{Ag} / \mathrm{SiO}_{2}$ dispersion (plano-em) as conductive glue. For each catalyst batch, two samples were examined at room temperature, one as-synthesized before the reaction and one after the reaction (marked with an asterisk). All spectra were collected after introduction to UHV without further treatment. Since the samples showed some charging (up to $7 \mathrm{eV}$ ), the binding energy scales are referenced to the binding energy of the $\mathrm{Al} 2 \mathrm{p}$ level at $74.6 \mathrm{eV}$; this value was reported for $\mathrm{Al}_{2} \mathrm{O}_{3}$ in literature[3]. We observe signals shifted to lower binding energy in $\mathrm{Ga} 2 \mathrm{p}(-2 \mathrm{eV}), \mathrm{Ga} 3 \mathrm{~d}(-$ $2 \mathrm{eV}$ ) and $\mathrm{Rh} 3 \mathrm{~d}$ signals (-2.1, and $2.5 \mathrm{eV}$ respectively). These generally appear more pronounced in spectra collected after catalytic testing indicating the formation of metallic $\mathrm{Ga}$ and $\mathrm{Rh}$ species under reaction condition. Based on the observed shifts we assign the observed signals to $\mathrm{Ga} / \mathrm{Ga}_{2} \mathrm{O}_{3}$ and $\mathrm{Rh} / \mathrm{RhO}_{\mathrm{x}}[4,5,6]$

The spectra of the bimetallic Ga-Rh model system were collected with the same setup and excitation energy. These samples were prepared at room temperature and in air by combining macroscopic amounts of Ga (99.99999 \%; Merck, former Sigma-Aldrich) and corresponding amounts of Rh ( $99.9 \%$, Goodfellow) in a W crucible (Lesker) attached to the sample stage of the XPS system. Temperature control of the $\mathrm{W}$ crucibles was achieved using resistive heating in combination with a K-type thermocouple spot-welded to the base of the crucible. The in vacuo-cleaning and preparation of the model surfaces included heating to temperatures as high as $580^{\circ} \mathrm{C}$ to facilitate homogeneous alloy formation and to decompose the passivating Ga oxide film formed in air; carbonaceous impurities were removed by sputtering with $1 \mathrm{keV} \mathrm{Ar}^{+}$. The binding energy scale for these samples is referenced to the Fermi-energy using a detailed region scan of the valence region of $\mathrm{Rh}$ (111). To account for fields introduced by resistive heating, 
the binding energy of the Ga $3 \mathrm{~d}$ core level binding energy is fixed to $18.8 \mathrm{eV}$, the value observed without heating. The quantification of the XPS signals of the bimetallic model systems is conducted by referencing to a Rh (111) single crystal and pure Ga. No temperature-, or composition-dependent shifts are observed in the $\mathrm{Rh} 3 \mathrm{~d}$ core level signals. Spectra are shown in Supplementary Figure S11.
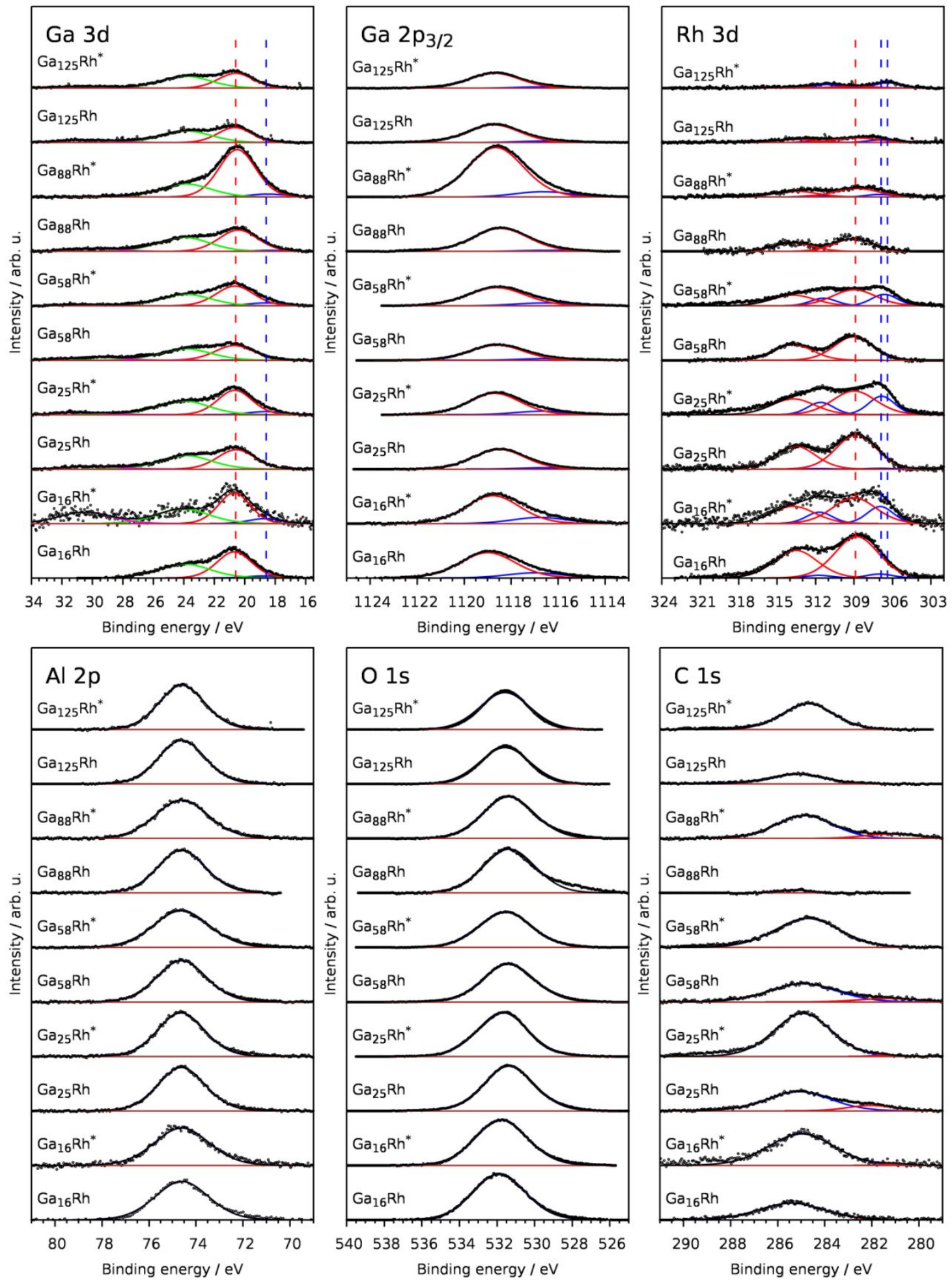
Figure S11: Al 2p, $O$ 1s and C 1s XP spectra of AlOx-supported SCALMS samples. Asterics indicate spent catalysts.

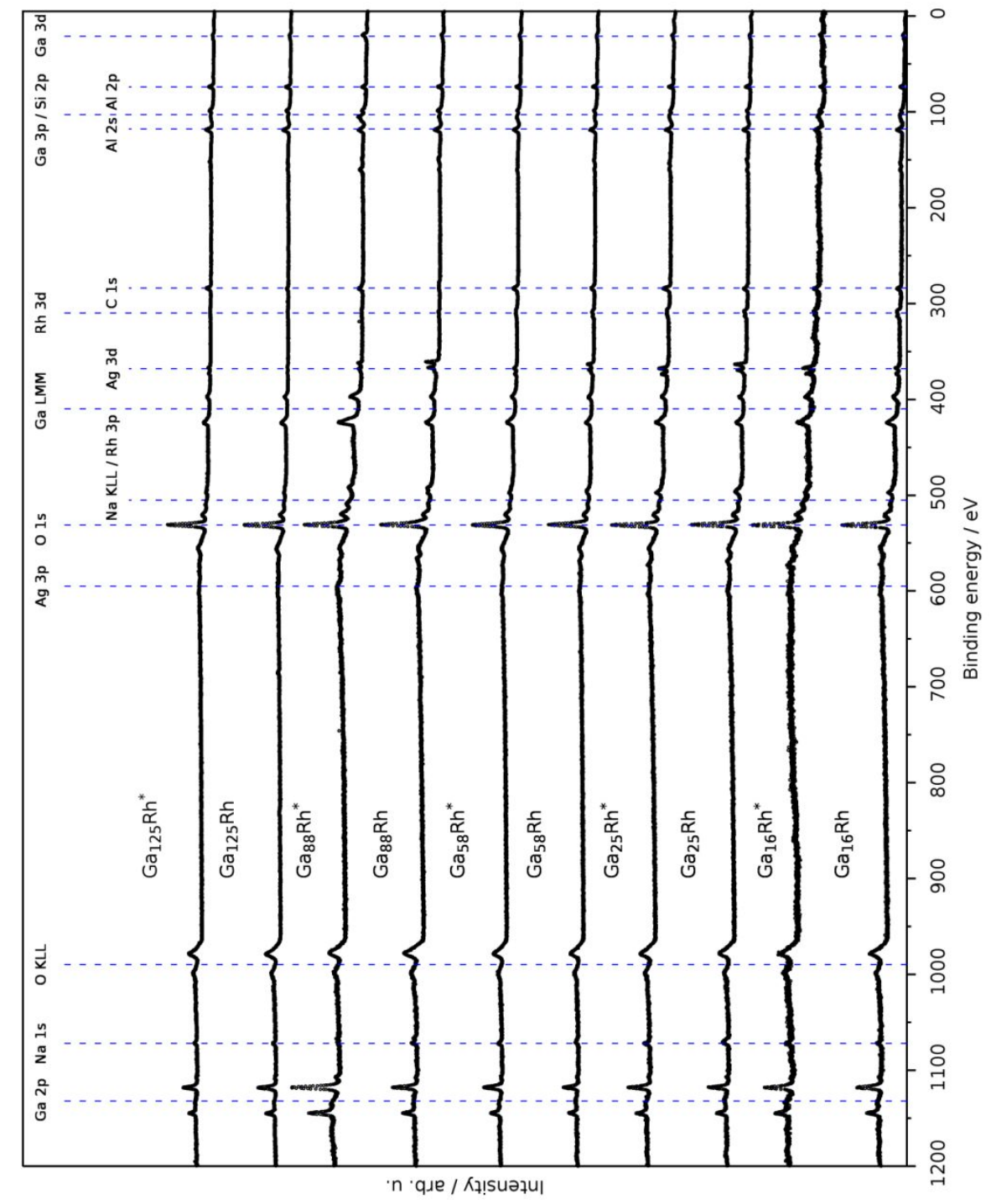

Figure S12: Survey XP spectra of AlOx-supported SCALMS samples. Asterics indicate spent catalysts. 

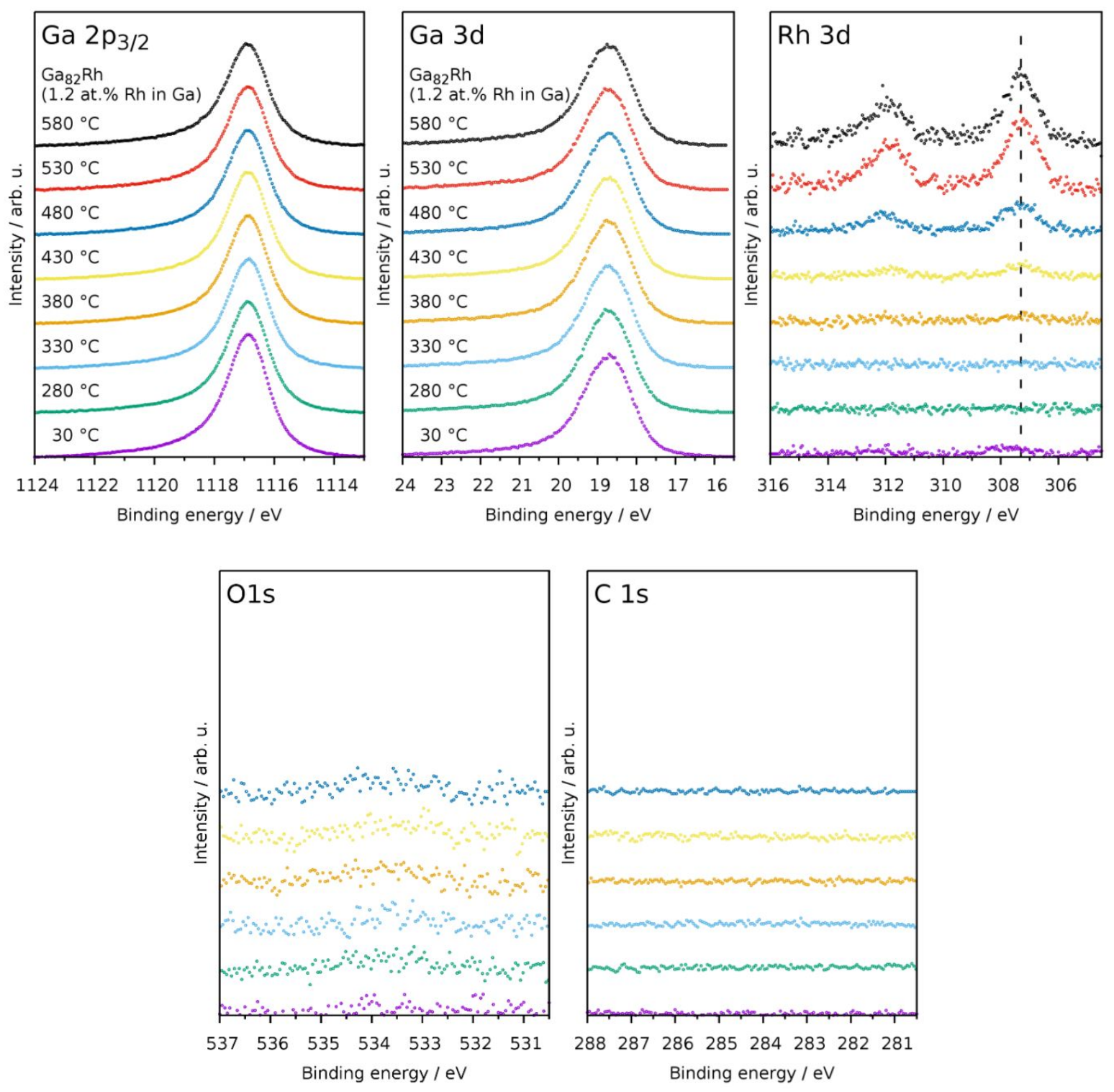

Figure S13: $G a 2 p_{3 / 2}, O$ 1s and $C$ 1s spectra collected from the $G a_{82} R h$ alloy droplet. The data was scaled to normalized Ga $3 d$ intensity for display. 


\section{TEM Analysis}

\section{(Scanning) transmission electron microscopy (method)}

The model samples compatible for TEM studies were prepared as described above. After deposition the samples are transferred via ambient condition and inserted into the TEM. Typically, a 3-5 $\mathrm{nm}$ thick oxide layer is present at the surface of the nanoparticles. Storage in ambient condition for up to a week does not seem to result in an increase of the oxide layer thickness.

(Scanning) transmission electron microscopy (S/TEM) studies were performed on a $\operatorname{Titan}^{3}$ Themis microscope operating at either $200 \mathrm{kV}$ or $300 \mathrm{kV}$. The TEM is equipped with $\mathrm{C}_{\mathrm{s}}$-correctors both at the illumination and imaging side, along with a Super-X energy dispersive X-ray (EDX) detector and a GIF Quantum ERS (spectrometer). The Super-X detector comprises four silicon drift detectors (SDD) symmetrically placed around the optical axis, close to the sample area, with a detection solid angle of about $0.9 \mathrm{sr}$. All four signals are combined into one spectrum to improve the collection efficiency in spectrum imaging (SI) acquisition. In the STEM imaging and SI experiments, the probe-forming semiangle was set to a value of $15.7 \mathrm{mrad}$. A probe current of 200-500 pA and dwell time 30-50 $\mu$ s was used. High-angle annual dark-field (HAADF), ADF, annual bright-field (ABF) and BF STEM images were simultaneously acquired along with the EDX signals. For high-resolution TEM (HRTEM) imaging, the image corrector was set to negative $\mathrm{C}_{\mathrm{s}}$ imaging (NCSI) condition [7], with the first pass band of the phase contrast transfer function (PCTF) reaching out to a resolution of $1 \AA$. All electron diffraction data are elastic filtered, which were recorded by the GIF camera with energy select slit of 10 eV placed over the zero-loss (i.e., elastically scattered) electrons. Energy filtering removes most of the inelastically scattered electrons and thus greatly enhances the contrast of diffracted spots and rings, especially close to the central transmitted beam, e.g., the first broad diffraction ring of solid amorphous or liquid phase, which would be otherwise very difficult to locate, quantify and interpret.

\section{Identification of the nanocrystal phase}

The nano-crystallites phase is assigned based on both the chemical composition (from EDX maps) and diffraction patterns. The local Rh concentration evaluated from summed EDX signals of the Rh-rich crystallites in the big Ga particle amounts to $12-15$ at. \%. This measured value can be slightly underestimated due contributions from amorphous Ga overlapping in projection direction. Three of the known candidate phase $[8,9,10]$, namely, $\mathrm{Ga}_{16} \mathrm{Rh}_{3}\left(15.9 \mathrm{Rh}\right.$ at. \%), $\mathrm{Ga}_{21} \mathrm{Rh}_{4}\left(16 \mathrm{Rh}\right.$ at. \%) and $\mathrm{Ga}_{9} \mathrm{Rh}_{2}$ (18.2 Rh at. \%) fit into this range. Comparing the position and intensity of the diffraction lines of the three phases with the experimental ring pattern, the strong lines seem to all fit. Upon closer inspection, large amount of minor lines expected in the $\mathrm{Ga}_{9} \mathrm{Rh}_{2}$ phase cannot be identified, while both $\mathrm{Ga}_{16} \mathrm{Rh}_{3}$ and 


\section{Supporting Information}

$\mathrm{Ga}_{21} \mathrm{Rh}_{4}$ seem to match almost perfectly to the experimental pattern (Fig. S12, only $\mathrm{Ga}_{16} \mathrm{Rh}_{3}$ phase superimposed).

While $\mathrm{Ga}_{9} \mathrm{Rh}_{2}$ (space group $P c$ ) take the form of the pristine $\mathrm{E}_{9} \mathrm{~T}_{2}$ phase $(\mathrm{E}=\mathrm{Al}$ or $\mathrm{Ga}, \mathrm{T}=$ transition metal), with building blocks of [RhGa9] antiprism polyhedral, the $\mathrm{Ga}_{16} \mathrm{Rh}_{3}$ (or $\mathrm{Ga}_{64} \mathrm{Rh}_{12}$, space group Ccca) and $\mathrm{Ga}_{21} \mathrm{Rh}_{4}$ (or $\mathrm{Ga}_{63} \mathrm{Rh}_{12}$, space group Cmca) are closely related to the $\mathrm{Ga}_{5} \mathrm{Pd}$ phase, with building blocks of [RhGa10] icosahedral cages sharing corners. The small difference of the $\mathrm{Rh}$ concentration in these two phases can be understood as result of stacking polymorphism. Indeed, stacking disorder is very frequently observed by HRTEM images in our samples.

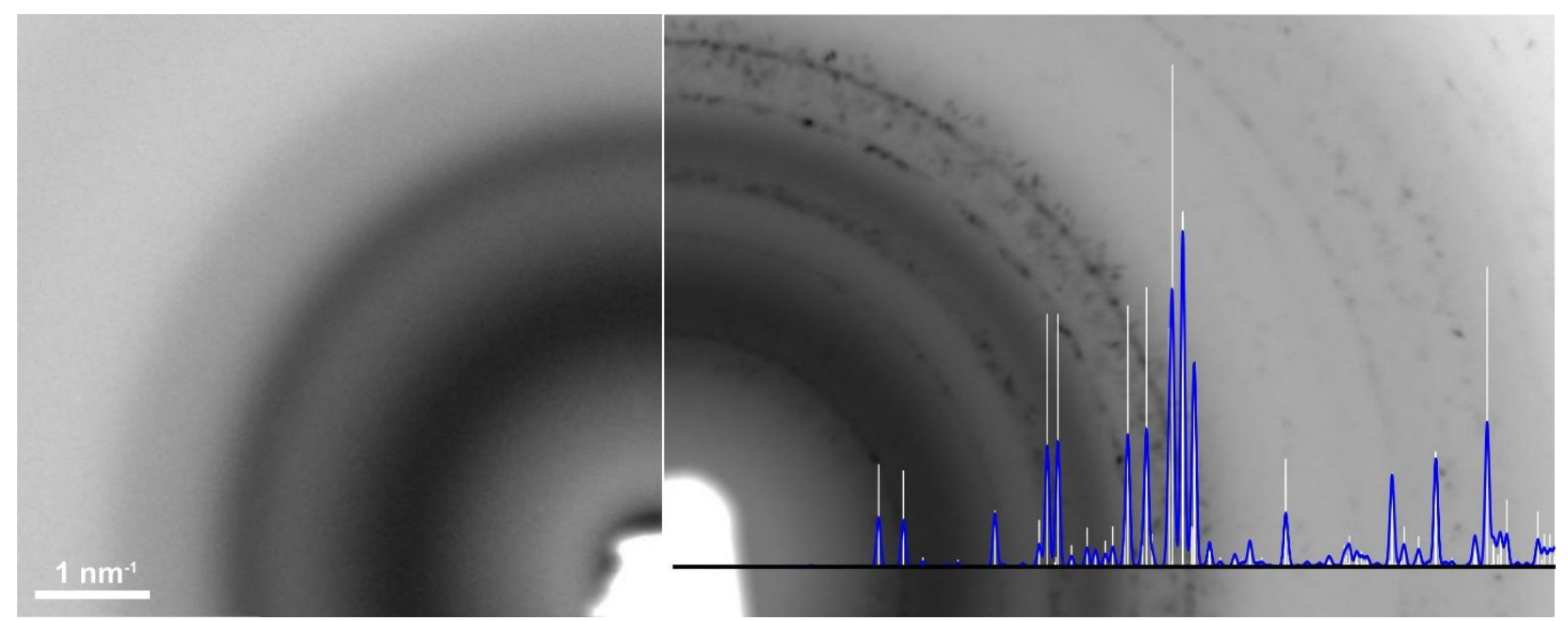

Figure S14: Crystal phase analysis with electron diffraction. The experimental zero-loss filtered electron diffraction patterns of pure Ga particles (left half) and a sample with average Rh content of 2.5 at. \%. The kinematic powder diffraction intensities (white lines) and calculated nano-crystalline diffraction intensities (assuming isotropic round particle with diameter of $20 \mathrm{~nm}$ ) with $G a_{16} R h_{3}$ phase (ICSD No. 415871) are superimposed on the right half. Contrast of the patterns is inverted and brightness scaled for better visualization. 


\section{$\underline{\text { Rh concentration dependent size and shape of the particles (room temperature) }}$}

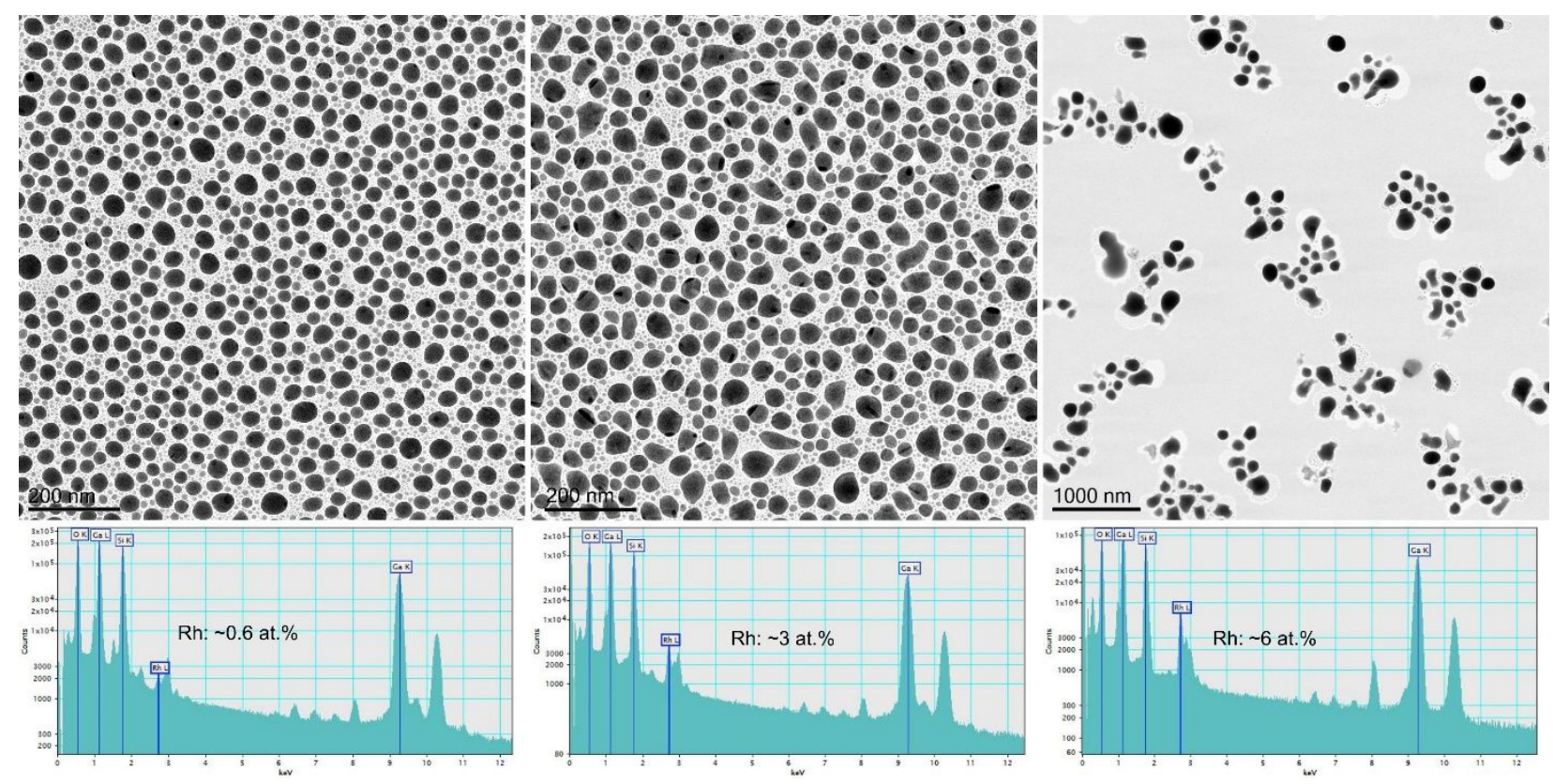

Figure S15: BF-TEM images of sample with (left) Rh 0.6 at. \%, (middle) Rh 3 at. \% and (right) Rh 6 at. \%. The corresponding EDX spectra (measured with a beam illuminated area of $8 \mu \mathrm{m}$ ) are show at the bottom of each image. With increasing Rh concentration, the shape of the particles become more irregular and the size of the particles increases (notice the larger scale bar in the right most image).

\section{$\underline{\text { In situ heating and electron diffraction }}$}

In situ heating experiments were carried out using a Gatan Heating Holder (Model 652). With this holder, temperature is measured by a thermocouple integrated into the furnace. Independent temperature measurement and comparison to chip-based heating holder was carried out previously $[11,12]$. In the experiments, temperature was raised manually by increasing the current send through the furnace at the tip, so that the sample was heated up slowly in a stepwise manner (steps of $\sim 100^{\circ} \mathrm{C}$ ). Each ramp took about $1 \mathrm{~min}$, which should be long enough to reach a steady and homogeneous temperature at the sample region. The temperatures at each step was held at least $1 \mathrm{~min}$. In particular, the temperature was hold for more than $10 \mathrm{~min}$ at about $400{ }^{\circ} \mathrm{C}$ for the sample with $\mathrm{x}=36$, and at about $300{ }^{\circ} \mathrm{C}, 500{ }^{\circ} \mathrm{C}$ and 580 ${ }^{\circ} \mathrm{C}$ for the sample with $\mathrm{x}=105$. The temperature was logged manually against the image frame numbers with an uncertainty of a couple of seconds. A short (up to $10 \mathrm{~s}$ ) and small (typically $10{ }^{\circ} \mathrm{C}, \max 40^{\circ} \mathrm{C}$ ) overshooting of temperature at the end of each ramp step can happen. We estimate the uncertainty of temperature for the given frames as shown in Fig. 1 (main manuscript) to be $\pm 10^{\circ} \mathrm{C}$.

To inspect the melting of the nanocrystallites, low dose zero-loss filtered selected area electron diffraction (SAED) was carried out in the range from RT to $540^{\circ} \mathrm{C}$. A $1.25 \mathrm{nA}$ electron beam was spread over a large sample area of about $8 \mu \mathrm{m}$ in diameter. Under this condition, the beam dose rate is about $1.5 \mathrm{e}^{-} / \AA^{2} \cdot \mathrm{s}$. Due to the huge number of diffracting nanocrystallites, and zero-loss energy filtering, 
diffraction patterns with very high contrast can be recorded at $10 \mathrm{fps}$. BF-TEM images taken before and after the in situ experiment, show unaltered particle morphologies in regions illuminated by electrons during low-dose in situ electron diffraction at elevated temperatures (Fig. S14). Therefore, potential beam induced effects during the in situ diffraction study of the melting behavior can be safely neglected.

In contrast, we have observed highly reproducible electron beam induced effects during in situ TEM imaging experiments, which require a much higher electron dose. Ga was "repelled" from the electron beam illuminated area at a beam dose rate of $50-5000 \mathrm{e}-/ \AA^{2} \cdot \mathrm{s}$ and typical total experimental time of 10 $-20 \mathrm{~min}$. This phenomenon was found to be dose dependent and independent of the supporting substrate $\left(\mathrm{SiO}_{2}\right.$ or $\left.\mathrm{SiN}\right)$ and is very likely related to carbon contamination during imaging in the vacuum of the TEM column (in the range of $10^{-7} \mathrm{mbar}$ ), which may have altered the phase equilibrium and diffusion behavior of the atoms.

According to the equation of dose-limited resolution [8]:

$$
\delta=(S N R)(D Q E)^{-\frac{1}{2}} C^{-1}(F D / e)^{-1 / 2}
$$

and typical parameters in (diffraction contrast) BF-TEM observations [8], a resolution of $5 \mathrm{~nm}$ requires a minimum dose of $\sim 10 \mathrm{e}^{-} / \AA^{2}$. Considering in situ observation, at typically $3-10 \mathrm{fps}$, a dose rate of 50 $\mathrm{e}^{-} / \AA^{2} \cdot \mathrm{s}$ is the minimum requirement to observe the melting of Ga-Rh nano-particles in real space. Since under these conditions electron beam induced effects cannot be neglected the melting behavior of the precipitates have been studied by low-dose electron diffraction (see above).

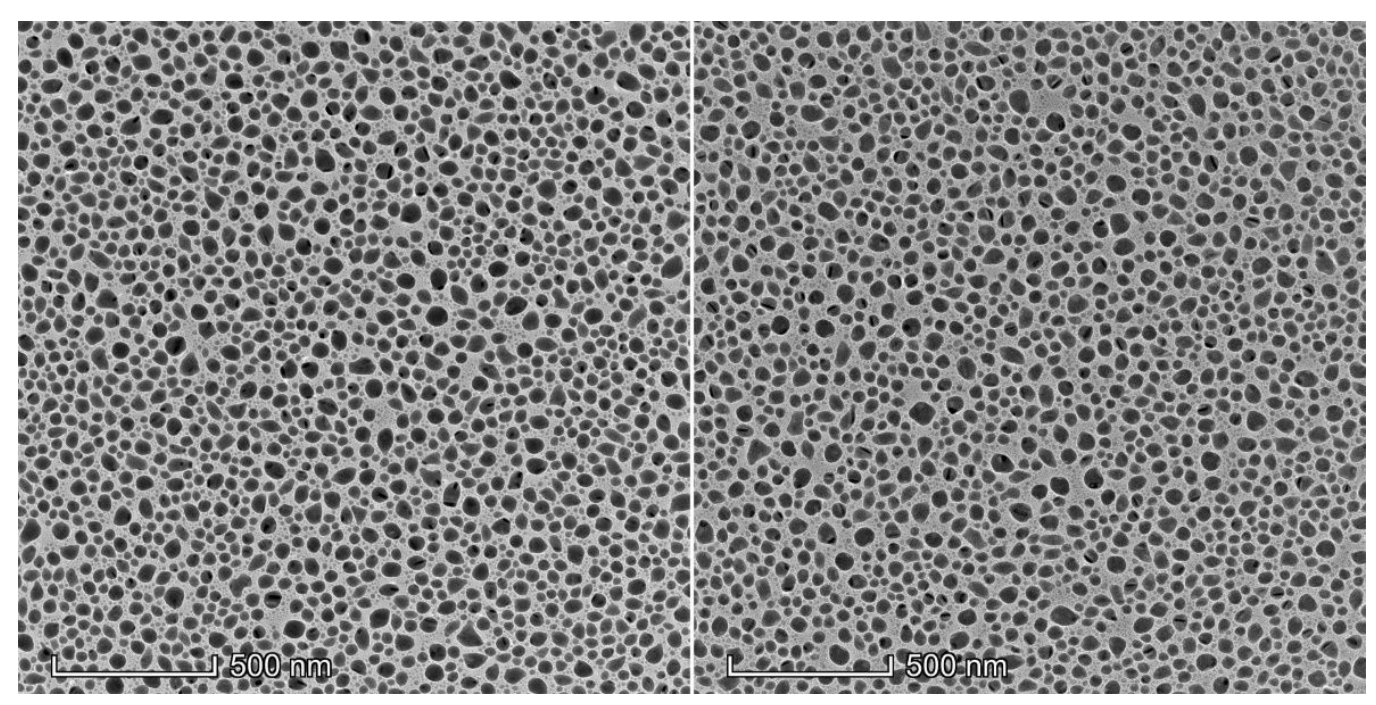

Figure S16: BF-TEM overview images of the sample before and after in situ heating and low dose SAED studies. Electron beam induced effects are not observable. 


\section{Super-saturated Rh-Ga amorphous solid phase and the oxide shell}

Super-saturated $\mathrm{Rh}-\mathrm{Ga}$ amorphous phase was observed when heating the sample with $\mathrm{x}=105(\mathrm{Rh}=0.9$ at. \%) up to $\sim 320{ }^{\circ} \mathrm{C}$ until the sharp crystal rings completely fade out, and then slowly cool down to room temperature. Figure S17 shows the STEM-EDX and electron diffraction results. The lack of sharp diffraction rings like that in Fig. 5 and Fig. S1 and existence of the 3 broad diffuse rings suggest the particles take amorphous solid phase. Formation of the super-saturated Rh-Ga amorphous solid phase is likely related to the existence of the oxide shell. Figure S18 shows the STEM-EDX and electron diffraction results of the same sample, measured at RT after it has been heated to $580{ }^{\circ} \mathrm{C}$. The oxide shell is no more observable, and the typical two-phase microstructure recovered.
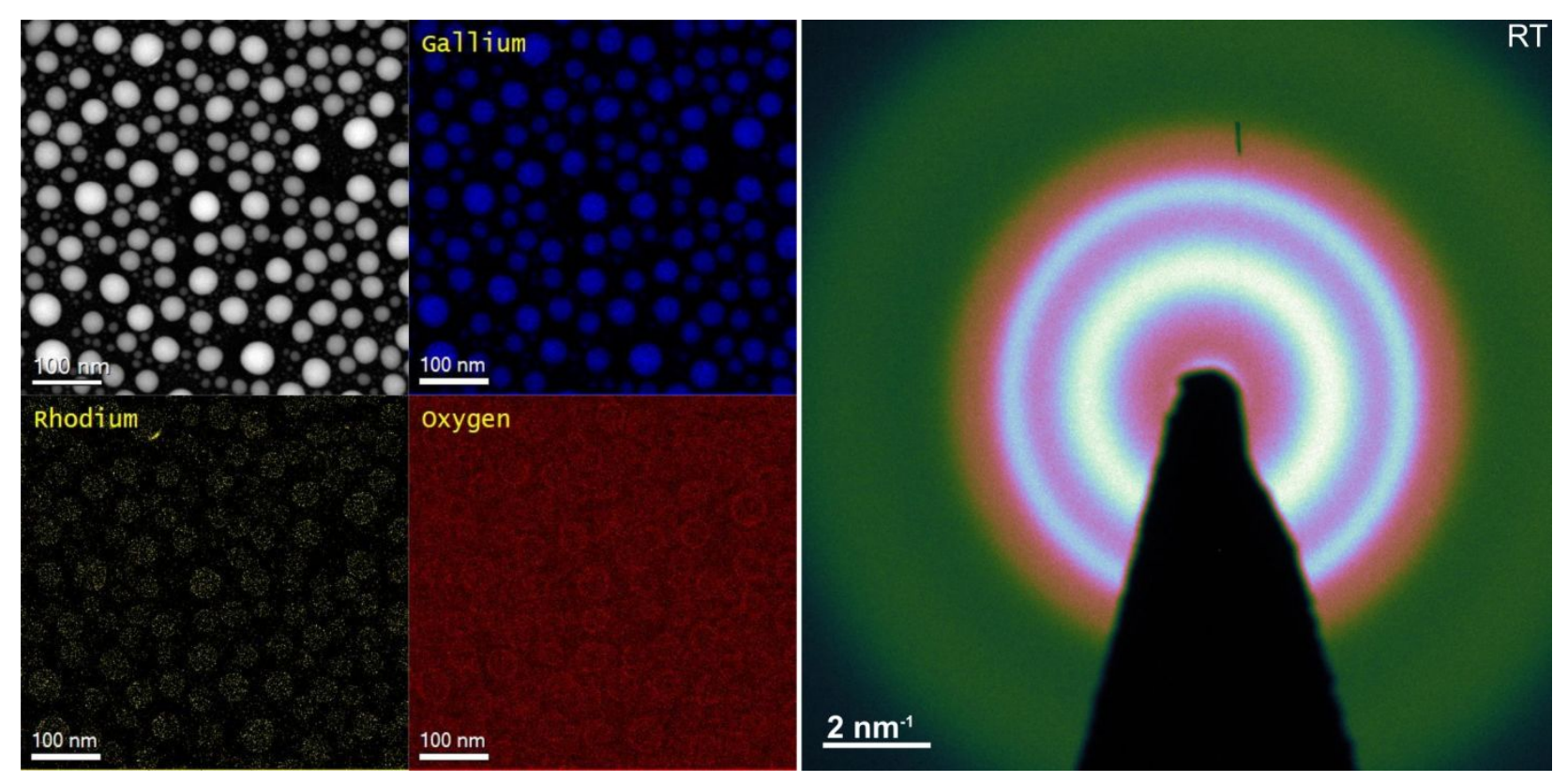

Figure S17: (left) STEM-EDXS maps: Gray (simultaneously acquired STEM Z-contrast image), yellow (Rh), red (oxygen) and blue (Ga). The oxides shell can be seen clearly in the oxygen map. Electron diffraction measured at $R T$ (middle) show amorphous ring pattern. 

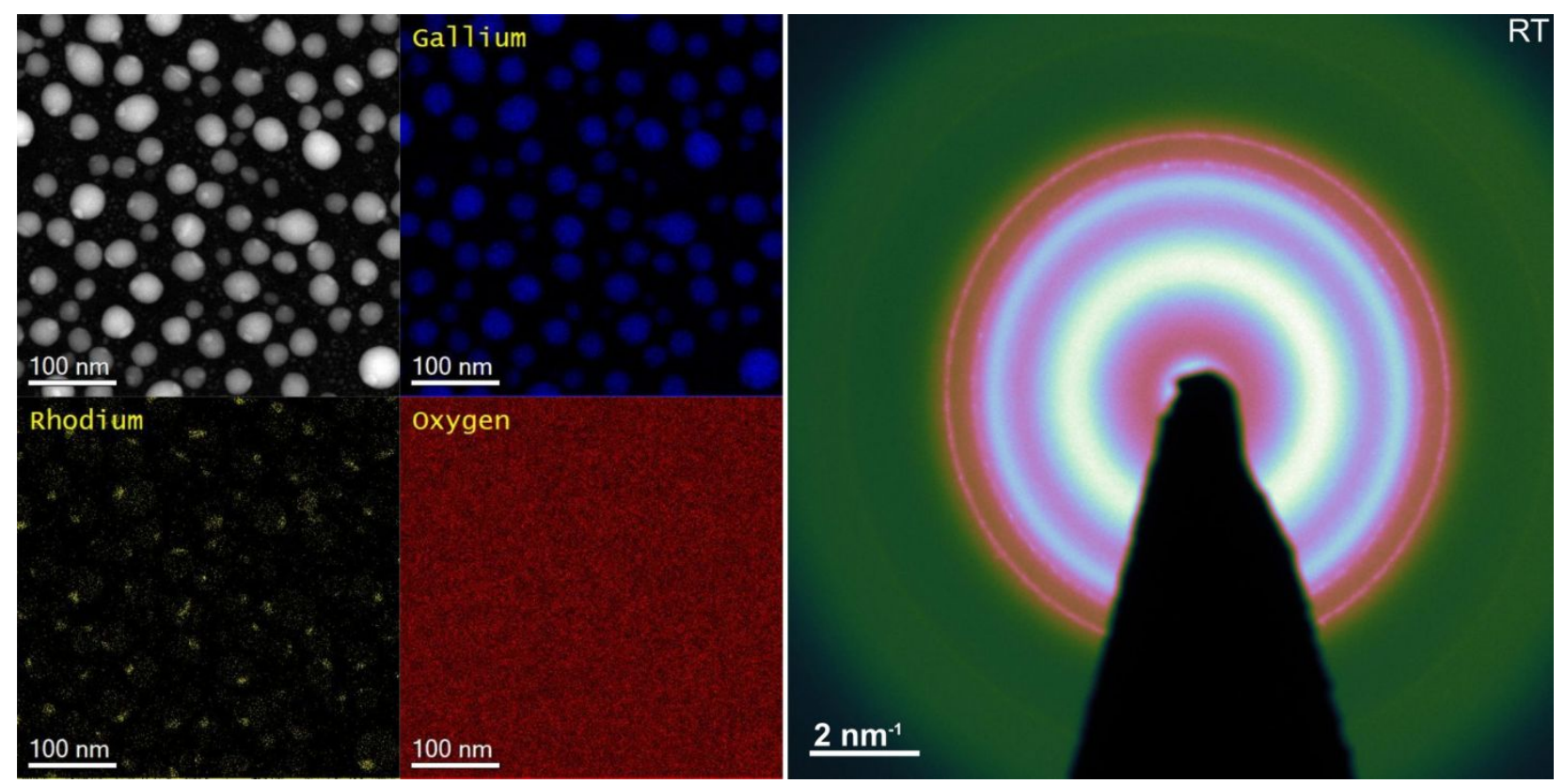

Figure S18: (left) STEM-EDXS maps: Gray (simultaneously acquired STEM Z-contrast image), yellow (Rh), red (oxygen) and blue ( $G a)$. The oxides shell was removed after the sample has been heating to $580^{\circ} \mathrm{C}$. Electron diffraction measured at RT (middle) show sharp crystal rings.

\section{$\underline{\text { The broad diffraction rings }}$}

The diffraction patterns from the sample with $\mathrm{x}=105$ at $\mathrm{RT}$ and $540 \pm 10^{\circ} \mathrm{C}$, and the azimuth averaged profile is show in Fig. S17. The profile is fitted by five Gaussian peaks. While the two broad background peaks are due to the amorphous $\mathrm{SiO}_{2}$ membrane, the superimposed three peaks at about $\mathrm{q}=2.6 \mathrm{~nm}^{-1}$, $4.2 \mathrm{~nm}^{-1}$ and $5.1 \mathrm{~nm}^{-1}$ are attributed to disordered Ga-Rh phase. At $540 \pm 10^{\circ} \mathrm{C}$, the second and third peaks are reduced dramatically. 

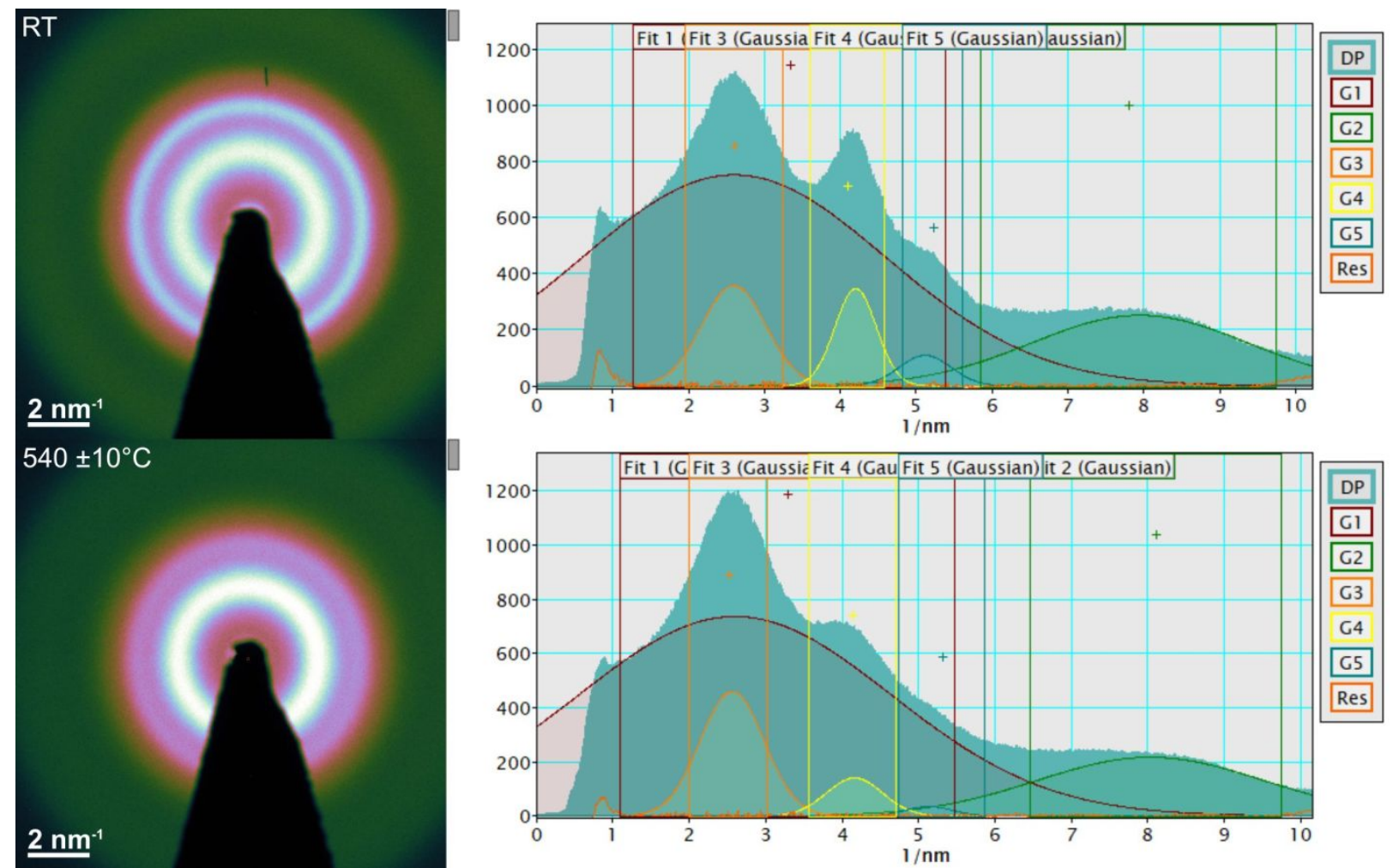

Figure S19: Diffraction pattern and the azimuth integrated intensity profile with Gaussian peak fitting superimposed from solid amorphous Ga-Rh phase (top) and liquid Ga-Rh phase.

In addition to the sharp diffraction rings from crystallites, at least two broad diffraction rings can be seen throughout the series at positions $\mathrm{q}=2.6 \mathrm{~nm}^{-1}$ and $4.2 \mathrm{~nm}^{-1}$, with the second marked by the white arrows in the patterns. They are very close to expected positions of disordered (i.e., amorphous solid and/or liquid) Ga phases [13]. Due to the structural similarity of amorphous solid phase and liquid phase of $\mathrm{Ga}$, and expectedly also for the Rh-poor Ga-Rh system, it is not immediately obvious to discriminate the two possible phases from the diffracted intensities. Nevertheless, the intensity ratio between the second and first broad ring, which is related to the different structure factor of amorphous solid and liquid phase [14], could serve as a qualitative indication of liquid or solid phase. In case of the sample with $\mathrm{x}=36$, this ratio did not change at all upon ramping the temperature from 480 to $530^{\circ} \mathrm{C}$ (the highest temperature tested for this sample) and changed by only less than $10 \%$ when compared to RT results. We deduce, therefore, that a fully liquid phase is present in samples with $\mathrm{x}<36$ above $530{ }^{\circ} \mathrm{C}$. In the case of the sample with $\mathrm{x}=105$, this ratio at temperatures above $\sim 350^{\circ} \mathrm{C}$ shows a dramatic reduction of more than $50 \%$ compared to the ratio at RT (cf. ESI Video 2), supporting that the particles with $\mathrm{x}=105$ are in full liquid state at the catalysts working temperatures. In the diffracted intensities normalized to the first diffraction ring (Fig. 5e) the intensity of the second ring 
decreased significantly and broadened at temperatures of $420 \pm 10^{\circ} \mathrm{C}$ and $540 \pm 10^{\circ} \mathrm{C}$. The existence of this intermediate Ga-Rh amorphous solid phase might be a size effect. From these observations, we conclude that at the working temperature conditions, only the low $\mathrm{Rh}$ concentration samples are in a fully liquid phase, which is consistent to the conclusion obtained from XPS and simulations.

Video S1. Electron diffraction series of sample with $\mathrm{x}=36$, temperature $400-530^{\circ} \mathrm{C}, 20 \mathrm{x}$ accelerated. Video S2. Electron diffraction series of sample with $\mathrm{x}=105$, temperature $550-\mathrm{RT}{ }^{\circ} \mathrm{C}, 20 \mathrm{x}$ accelerated.

\section{COMPUTATIONAL METHODS}

All density-functional theory calculations were performed using the "Vienna Ab Initio Simulation package" (VASP) employing the projector augmented wave (PAW) method to represent the atomic cores and a plane wave basis set $[15,16,17]$. Exchange-correlation effects were treated within the GGA approach applying the functional of Perdew, Burke and Ernzerhof (PBE) [18]. Dispersion interactions were incorporated in the investigation of adsorption processes by the D3 correction of Grimme et. al. [19].

Ab initio DFT-based molecular dynamics (AIMD) simulations were conducted to study the behavior of the liquid $\mathrm{Ga} / \mathrm{Rh}$. The liquid-vacuum interface was represented by a periodic slab model with a tetragonal unit cell (12.69x12.69x36.15 $\AA$ ) consisting of $162 \mathrm{Ga}$ and $18 \mathrm{Rh}$ atoms and a vacuum layer of $\sim 12 \AA$ in z-direction (perpendicular to the surface) to decouple periodic images. In calculations without any adsorbates an energy cutoff for the plane wave basis set of $350 \mathrm{eV}$ was used. The equations of motion were integrated with a Verlet algorithm in time steps of $10 \mathrm{fs}$, which was previously shown to be sufficient for a system containing $\mathrm{Ga}$ and a heavier metal component (Pd, Rh) [20, 21]. After equilibration for at least 10 ps, a Nosé-Hoover thermostat [22] was employed to simulate a canonical ensemble at $450{ }^{\circ} \mathrm{C}$. A Fermi-smearing was used with a smearing parameter corresponding to the temperature conditions [23]. The first Brillouin zone was sampled by a $\Gamma$-containing $2 \times 2 \times 1 \mathrm{k}$-point mesh. To obtain good energy conservation during the AIMD simulation, the SCF convergence criterion was set to $10^{-7} \mathrm{eV} .15$ trajectories were sampled with an overall simulation time of $5.88 \mathrm{~ns}$. Each trajectory was running for at least $240 \mathrm{ps}$, the longest trajectory for $638 \mathrm{ps}$. These AIMD simulations showed that the time evolution of the mean square displacement (MSD) function of the Ga and $\mathrm{Rh}$ atoms from their initial position exhibits a linear behavior for both species indicating the catalyst to be in a liquid state in the simulations (see ESI, Fig. S18). Similar to the previously studied GaPd system [21], a layered catalyst surface structure in combination with a Rh surface 
depletion can be observed from the corresponding density profile along the direction perpendicular to the surface (the z-direction) which represents the probability of finding a $\mathrm{Ga}$ or $\mathrm{Rh}$ atom in intervals of $0.1 \AA$ in that direction (depicted in ESI, Fig. S19). Our calculations reveal that less than $0.02 \%$ of the alloy surface atoms are $\mathrm{Rh}$ atoms if the first maximum of the Ga-density is used to define the first layer (or $0.7 \%$ if the first minimum of the Ga density is used). Therefore, it can be assumed that isolated $\mathrm{Rh}$ atoms appearing dynamically at the surface are responsible for the catalytic reaction with the approaching reactants.

The adsorption of $\mathrm{CO}$ was investigated using the same tetragonal cell, however containing $178 \mathrm{Ga}$ atoms and $2 \mathrm{Rh}$ atoms, one on each surface of the slab with one or two adsorbed $\mathrm{CO}$ molecules on-top of the $\mathrm{Rh}$ atoms. For this system, the time step in the MD was decreased to $2 \mathrm{fs}$. Additionally, the plane wave cutoff energy was set to $450 \mathrm{eV}$. We obtained vibrational spectra by computation of the Fourier transform of the velocity-velocity autocorrelation function using the trajectory analyzer code TRAVIS $[24,25]$. For $\mathrm{Rh}(\mathrm{CO})_{2}$ five trajectories were sampled, each trajectory for $20 \mathrm{ps}$, starting from different initial geometries. The obtained power spectra were then averaged. For the RhCO species the power spectrum is computed from a trajectory running for $38 \mathrm{ps}$.

To test if adsorption of species which are involved in the catalytic process can retain the catalytically active center at the surface, we placed different adsorbates at the $\mathrm{Rh}$ atom, namely propylene, a propyl residue and an additional hydrogen atom or two hydrogen atoms, at the beginning of our simulation. The time evolution of the z-position (Fig. S20) shows that as long as the adsorbate is bound to the Rh atom, the latter is kept at the surface until the adsorbate desorbes. After desorption, the Rh atoms directly diffuse away from the surface. In these simulations the timestep was reduced to 1 fs and the mass of the hydrogen atoms was set to the deuterium mass.

The coverage dependence of the $\mathrm{CO}$ stretch frequency on top-Rh was assessed by computing the vibrational frequencies of $\mathrm{CO}$ on a $\mathrm{Rh}(111)$ surface using varying super cell sizes, namely $2 \times 2$ (3/4 and 1/4 ML with 3 and 1 CO molecules, respectively), 3x3 (1/9 ML) and 4x4 (1/16 ML) in harmonic approximation using a finite differences approach with a displacement of $0.01 \AA$ in all spatial directions. The $\mathrm{Rh}(111)$ surface was modeled by a 6 layer $\mathrm{Rh}$ slab with the three bottom layers fixed to the calculated bulk geometry (with a lattice constant of $3.79 \AA$ ), while the three surface layers were free to relax with an additional vacuum layer of $12 \AA$ in direction perpendicular to the surface. CO was adsorbed in top position for all coverages, however for $3 / 4 \mathrm{ML}$ the experimentally observed structure with one $\mathrm{CO}$ in top and two $\mathrm{CO}$ in threefold hollow positions was considered [26]. To obtain well converged forces the plane wave cutoff was set to $480 \mathrm{eV}$ and a SCF converge criterium of $10^{-8} \mathrm{eV}$ was chosen. The geometries were relaxed until the forces on all atoms became smaller than $0.01 \mathrm{eV} / \AA$. A Methfessel- 
Paxton smearing of first order with a smearing parameter of $\sigma=0.2 \mathrm{eV}$ was applied [27] with a $19 \mathrm{x} 19 \mathrm{x} 1$ k-point mesh for the $1 \mathrm{x} 1$ cell and corresponding sizes for larger cells.

To investigate the dehydrogenation of propane, a solid model system was created, that consists of a fcc$\mathrm{Ga}(\mathrm{IV})$ slab with an isolated Rh-adatom in a surface hollow position to mimic the situation in the liquid catalyst system (see Fig. S21). The Ga(IV) bulk structure is a high pressure fcc-Ga phase with a computed lattice constant of $a=4.18 \AA$. The bulk and the corresponding (100)-surface (as $3 \times 3 \times 3$ supercell) were relaxed with $\Gamma$-including $25 \times 25 \times 25$ and $8 \times 8 \times 1$ k-point meshes, respectively. For the 6layer surface slab (with $14 \AA$ vacuum), again the 3 bottom layers were kept fixed at the bulk geometry and structures were relaxed until the forces on all atoms became smaller than $0.001 \mathrm{eV} / \AA$. The SCF convergence criterion was set to $10^{-6} \mathrm{eV}$. Again, a Methfessel-Paxton smearing of first order with a smearing parameter of $\sigma=0.2 \mathrm{eV}$ was chosen. For geometry optimizations with adsorbates the forces were converged to less than $0.005 \mathrm{eV} / \AA$. Different sites for the additional Rh atom were tested, yielding that the most favorable position after geometry optimization is a slightly distorted hollow position in the first surface layer.

Transition states were determined using the climbing-image nudged elastic band method (cNEB) as implemented in VASP according to Henkelman et al. [28] with a force convergence criterion of 0.025 $\mathrm{eV} / \AA$. All other settings in the cNEB calculations are equal to the geometry optimizations of initial and final states. The highest energy image of the cNEB calculation was used as initial guess for a dimer search to further converge the transition states until the forces were lower than $0.01 \mathrm{eV} / \AA$. [29] Local minima and transition states were verified by vibrational analysis. Helmholtz free energy corrections were calculated in the simple harmonic limit using the thermochemistry module of the Atomic Simulation Environment (ASE) [30]. Here, the real vibrational frequencies of the adsorbate and the surrounding surface atoms were used to calculate the correction. Comparing the uncorrected DFT energies (see Fig. 4c) with the Helmholtz free energies, it is obvious that the reaction profile is only slightly changed. The overall reaction barrier remains almost the same. 


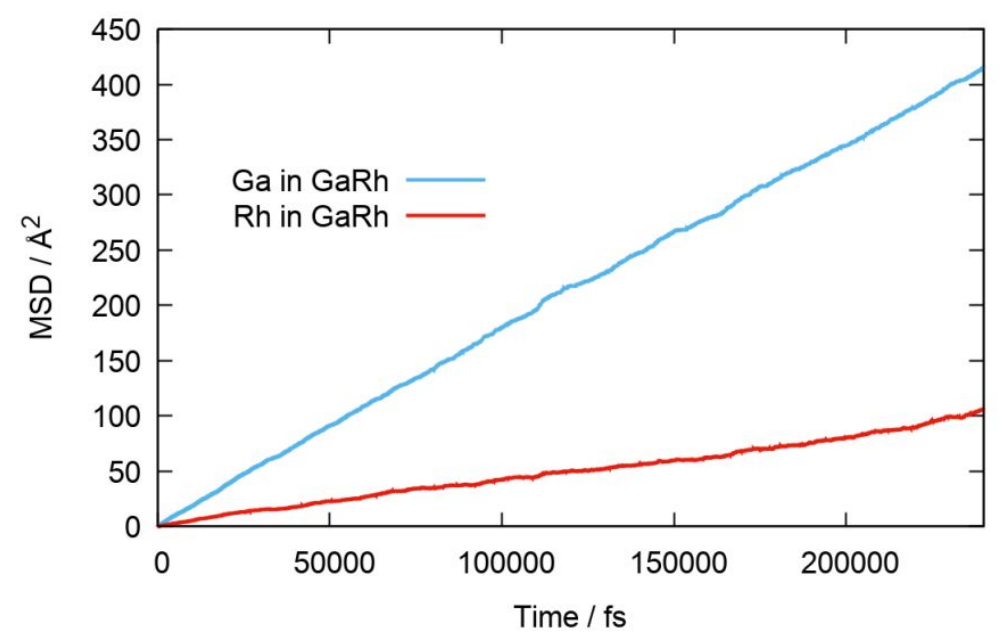

Figure S20: Calculated mean square displacement (MSD) of $\mathrm{Ga}$ and $\mathrm{Rh}$ atoms from their initial positions in liquid GaRh. The shown MSD is calculated as an average of all 15 calculated trajectories.

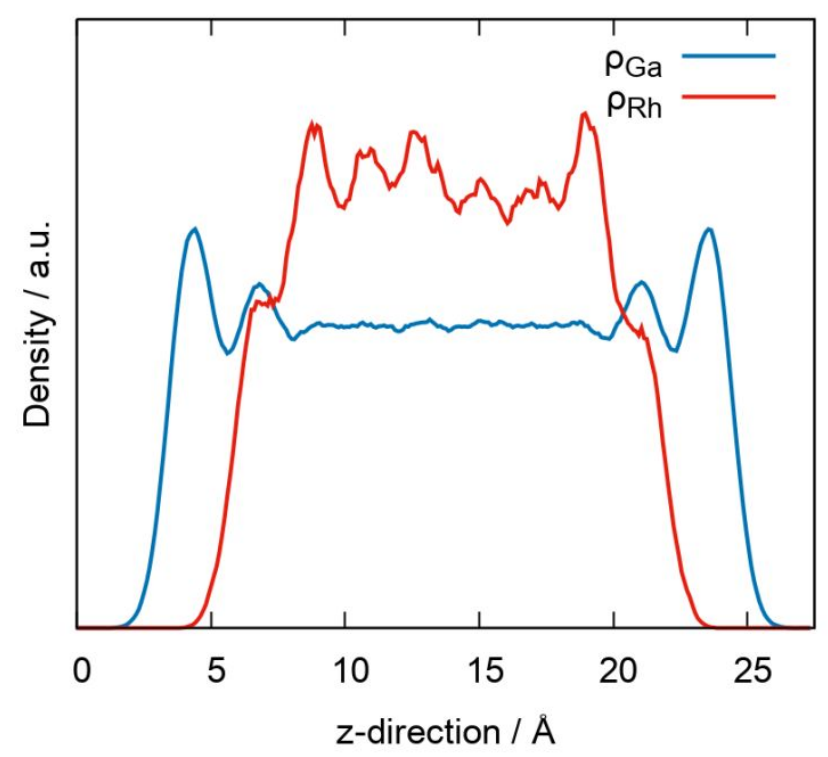

Figure S21: Simulated density profile for Ga and Rh perpendicular to a liquid GaRh (ratio 9) slab at $450{ }^{\circ} \mathrm{C}$ (a.u., arbitrary units). The probability of finding Ga or Rh atoms in intervals of $0.1 \AA$ along the z-direction is plotted. The Rh-density $\left(\rho_{\mathrm{Rh}}\right)$ is scaled such that values are comparable to the Ga density $\left(\rho_{\mathrm{Ga}}\right)$. Due to the smaller number of heavy Rh atoms, the Rh-density is not perfectly converged. 

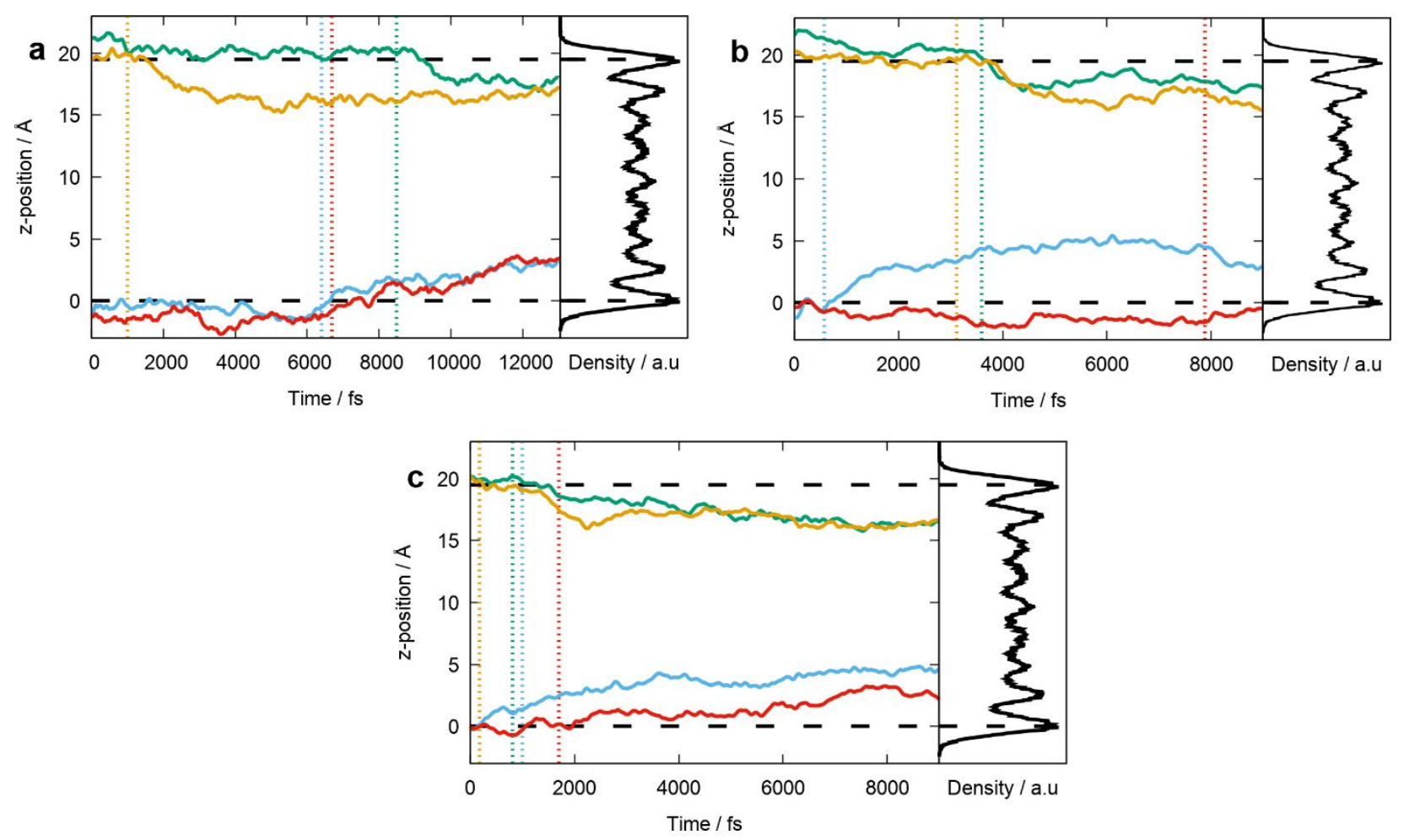

Figure S22: z-position of Rh atoms with different adsorbates as function of time. a, Propylene. b, Propyl residue and one hydrogen atom. c, Two hydrogen atoms. For each adsorbate two trajectories were sampled, thus there are two lines at the bottom and two at the top surface. Dashed vertical lines indicate the desorption (a) or the reaction of $\mathrm{H}$ and propyl to propane or of the two $\mathrm{H}$ atoms to $\mathrm{H}_{2}$ with subsequent desorption ( $\mathrm{b}$ and $\mathrm{c}$ ) for each trajectory in the corresponding color. The Ga-density is given as orientation. Horizontal dashed lines indicate the first maximum of the Ga density. In all cases the

$\mathrm{Rh}$ atoms are kept at the surface by the adsorbate and move into the slab after the adsorbate has desorbed.

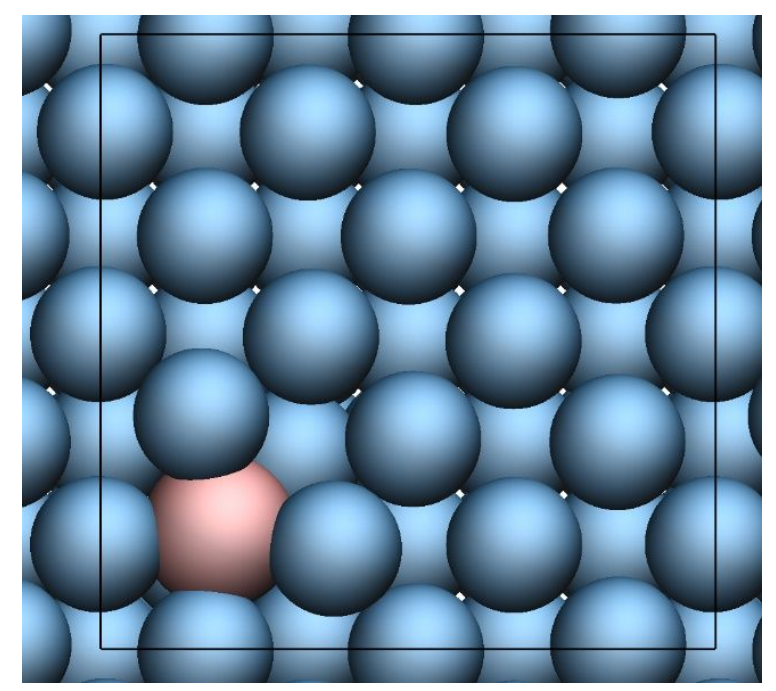

Figure S23: Top view on the solid model catalyst system; a fcc-Ga slab with one Rh adatom adsorbed in a slightly distorted fourfold hollow position. Ga atoms are depicted in blue, Rh atoms in light red. The black line indicates the surface unit cell. 


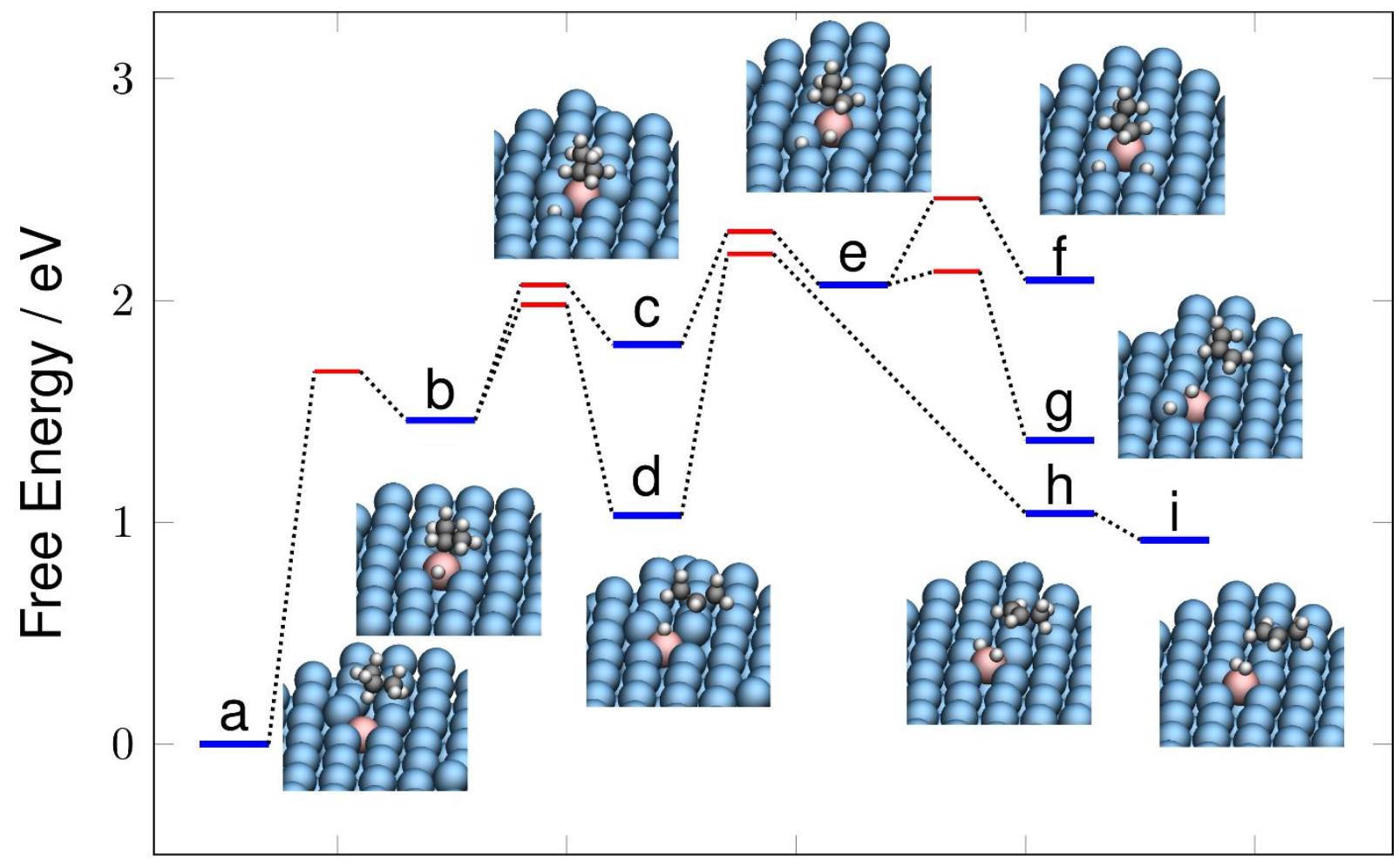

\section{Reaction coordinate}

Figure S24: Free energy diagram for the dehydrogenation of propane. Ga is depicted in blue, $\mathrm{Rh}$ in light red, $\mathrm{C}$ in black and $\mathrm{H}$ in white. Reaction intermediates are indicated by blue lines and transition states by red lines.

We estimated the uncertainty of the properties determined by the AIMD simulations by comparing the values we obtain from single trajectories with the one obtained as average over all trajectories.

1. Vibrational spectra: Five trajectories were sampled for the $\mathrm{Rh}(\mathrm{CO})_{2}$ vibrational spectrum, each simulated from different initial configurations. The average value of the $\mathrm{CO}$ vibrational frequency over all five trajectories is calculated to be 2002 and $1978 \mathrm{~cm}^{-1}$ for the symmetric and asymmetric $\mathrm{CO}$ stretching frequencies, respectively. From single trajectories we obtain for the peak maximum of the symmetric CO frequency values in the range of 2012-1998 $\mathrm{cm}^{-1}$ and for the asymmetric CO stretching value from 1982-1975 $\mathrm{cm}^{-1}$. Adding or removing single trajectories from the average has only minor impact on the average value.

2. MSD: To quantify the uncertainty of the MSD values we evaluated diffusion coefficients from the slope of the $\mathrm{x}$-and $\mathrm{y}$-component of the MSD for Ga in the 15 different trajectories. The average value for the $\mathrm{Ga}$ diffusion coefficient calculated from all trajectories is $3.81 * 10^{-5} \mathrm{~cm}^{2} \mathrm{~s}^{-1}$. The largest deviations from this value for single trajectories are 
$3.29 * 10^{-5} \mathrm{~cm}^{2} \mathrm{~s}^{-1}$ and $4.67 * 10^{-5} \mathrm{~cm}^{2} \mathrm{~s}^{-1}$. Again, adding or removing single trajectories from the average results only in minor deviations.

3. Z-positions of Rh atoms in the slab (see Figure 4a and Figure S20): For each adsorbate that was tested two trajectories starting from different initial configurations were sampled to test the reliability of the results. In all cases the two trajectories give qualitatively the same results as described in the main text.

Charge analysis was performed on the all-electron charge density using the Bader program as implemented in the VASP Code [31,32].

\section{INFRARED SPECTROSCOPY}

\section{Reactor setup for infrared measurements}

Diffuse reflectance infrared Fourier transform spectroscopy (DRIFTS) was performed using a homebuilt reactor system in combination with a Bruker Vertex 80v FTIR spectrometer. Figure S24 shows a section of the layout. The reactor chamber and Praying Mantis diffuse reflectance accessory (Harrick) are situated in the sample compartment of the spectrometer, which is evacuated during the measurements. By evacuating the complete optical path, we ensure high stability during long-term experiments. The reactor is equipped with $\mathrm{CaF}_{2}$ windows and a type $\mathrm{K}$ thermocouple in contact with the sample, which leads to excellent temperature control. CO (Linde, 4.7) and Ar (Linde 5.0) were dosed using mass flow controllers (MFCs, Bronkhorst), the pressure in the system is adjusted using three pressure controllers (PCs, Bronkhorst). The automatized operation of the system enables accurate and reproducible changes of temperature, pressure and gas composition in the system.

Prior to the pulse experiment, the sample was reduced at $450^{\circ} \mathrm{C}$ in 1 bar CO. To study the surface properties of $\mathrm{GaRh}$ supported on $\mathrm{Al}_{2} \mathrm{O}_{3}$, we exposed the samples to pulses of $\mathrm{CO}$ at 100, 200, 300, 400 and $450^{\circ} \mathrm{C}$. A sequence of five $\mathrm{CO}$ pulses was performed at each temperature in the following way: After 5 min CO dosing (15\% in Ar) at 1 bar the CO gas phase was removed to resolve features that are otherwise hidden underneath the broad rotational-vibrational structure of CO. This was achieved by evacuation ( $<10 \mathrm{mbar}, 1 \mathrm{~min}$ ) and subsequent Ar dosing (4 min) at 1 bar. The sample was heated in 1 bar Ar to $450{ }^{\circ} \mathrm{C}$ to remove all residual $\mathrm{CO}$ adsorbates, before continuing with the next pulse sequence at a different temperature. 


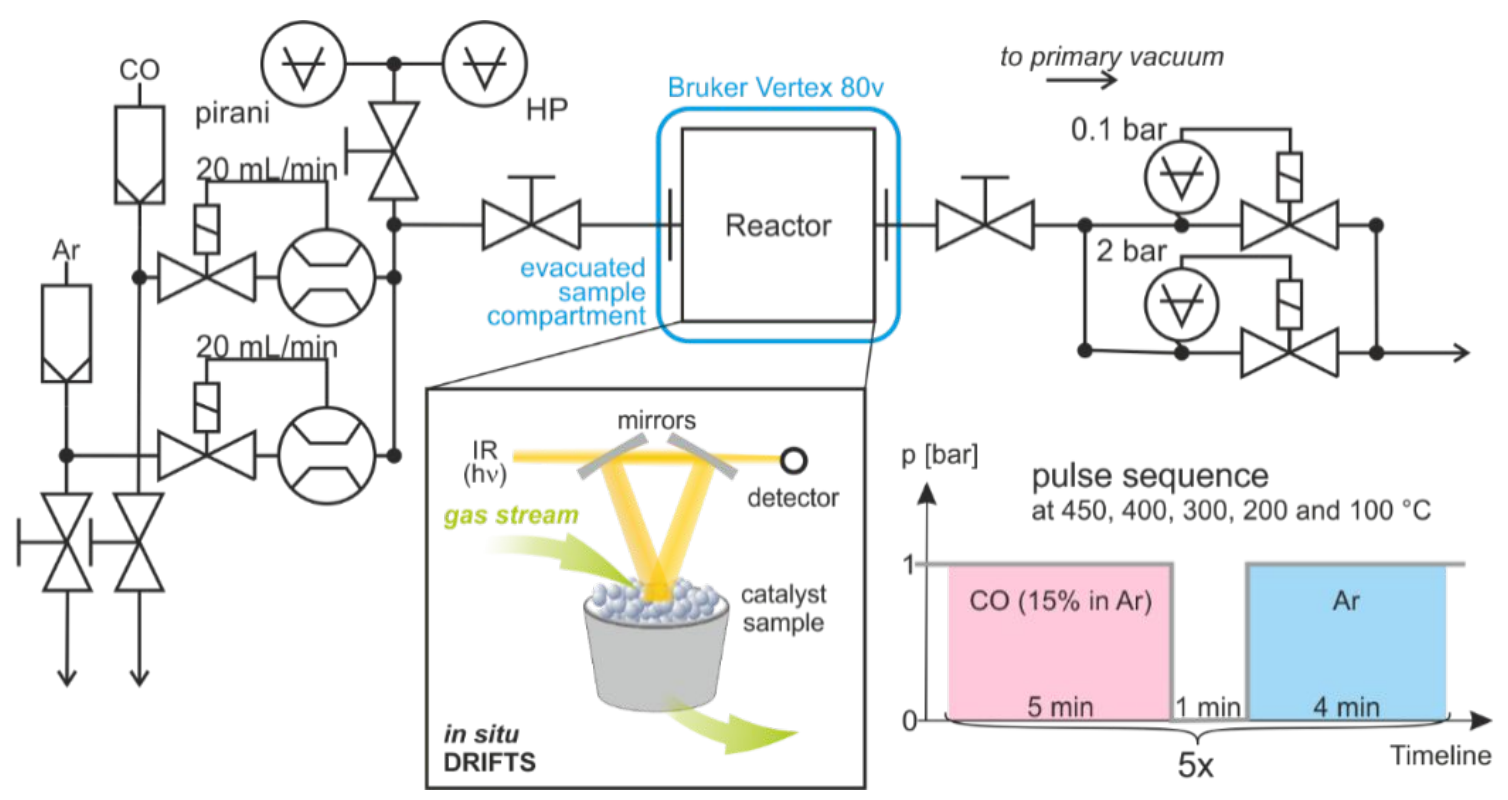

Figure S25: Schematic depiction of the reactor layout

All spectra were recorded with $20 \mathrm{~s}$ acquisition time. The background spectrum was recorded at $450{ }^{\circ} \mathrm{C}$ under Ar with an acquisition time of $2 \mathrm{~min}$. The spectra shown are normalized to compensate for changes in reflectivity upon heating and/or cooling and plotted as difference spectra $n_{\text {diff }}=n_{\text {seq }}-n_{\text {clean }}$ with $n_{\text {clean }}$ being a spectrum recorded at the respective temperature in $\mathrm{Ar}, \mathrm{n}_{\text {seq }}$ being the spectrum after $\mathrm{CO}$ exposure, and $\mathrm{n}_{\text {diff }}$ being the difference spectrum.

\section{$\underline{\text { DRIFT experiments }}$}

All DRIFT spectra were acquired immediately after removal of the last CO pulse at the respective temperature. Note that the spectra are not recorded under steady-state conditions and the peak intensities change during Ar purging, especially at higher temperatures. In the following, we neglect the temporal evolution but aim at the qualitative characterization of the species that are present.

First, we focus on the monometallic samples that are presented in the main manuscript. The $\mathrm{Rh} / \mathrm{Al}_{2} \mathrm{O}_{3}$ sample shows a pronounced double feature at $2093 \mathrm{~cm}^{-1}$ and $2023 \mathrm{~cm}^{-1}$. The peak intensities decreases with increasing temperatures, but the peak centers doe not shift. A smaller band, observed at $2065 \mathrm{~cm}^{-1}$ at $100{ }^{\circ} \mathrm{C}$, shifts to lower wavenumbers upon heating and disappears above $200{ }^{\circ} \mathrm{C}$. In accordance with the literature, the two signals at 2093 and $2023 \mathrm{~cm}^{-1}$ are assigned to the symmetric and asymmetric stretching frequency of $\mathrm{Rh}^{\mathrm{I}}(\mathrm{CO})_{2} \cdot[33,34,35]$ The smaller peak at $2065 \mathrm{~cm}^{-1}$ is assigned to on-top $\mathrm{Rh}^{0} \mathrm{CO}$ species, which is reported to show lower thermal stability than the $\mathrm{Rh}^{\mathrm{I}}(\mathrm{CO})_{2}$ dicarbonyl.[36] 
For the $\mathrm{Ga} / \mathrm{Al}_{2} \mathrm{O}_{3}$ sample, two broad bands evolve at $2021 \mathrm{~cm}^{-1}$ and $\sim 1880 \mathrm{~cm}^{-1}$ upon heating. The appearance of the bands and their temperature-dependence indicates the formation of $\mathrm{Ga}-\mathrm{H}$ species. Ga$\mathrm{H}$ peaks are typically observed above $250^{\circ} \mathrm{C}$ and increase in intensity upon heating as has been observed, for instance, on pure $\mathrm{Ga}$ and Ga-Pd catalysts.[37] Although no $\mathrm{H}_{2}$ was dosed during the experiment, residual $\mathrm{H}_{2} \mathrm{O}$ and $\mathrm{OH}$ groups on the support can lead to the formation of hydride species. The peak at $2021 \mathrm{~cm}^{-1}$ is characteristic for hydrides on metallic Ga, whereas the band at $\sim 1880 \mathrm{~cm}^{-1}$ is tentatively assigned to oxidic Ga species. This shows that Ga may not have been completely reduced under the present conditions (heating in $\mathrm{CO}$ to $450{ }^{\circ} \mathrm{C}$ ) in the case of the $\mathrm{Ga} / \mathrm{Al}_{2} \mathrm{O}_{3}$ sample. In contrast, no peak is visible at $\sim 1880 \mathrm{~cm}^{-1}$ on samples which contain $\mathrm{Rh}$ and full reduction to metallic Ga is found. This further confirms our assumption that oxidic Ga species are completely reduced in the presence of $\mathrm{Rh}$ under reductive conditions (see also statements above).

In Figure $\mathrm{S} 25$, we show the $\mathrm{CO}$ stretching frequency region of $\mathrm{Ga}_{25} \mathrm{Rh}_{1} / \mathrm{Al}_{2} \mathrm{O}_{3}$ and $\mathrm{Ga}_{125} \mathrm{Rh}_{1} / \mathrm{Al}_{2} \mathrm{O}_{3}$ samples. For the $\mathrm{Ga}_{25} / \mathrm{Rh}_{1} / \mathrm{Al}_{2} \mathrm{O}_{3} \mathrm{SCALMS}$ sample, the spectra show two pronounced peaks at 2099 and $2021 \mathrm{~cm}^{-1}$ at 100 and $200^{\circ} \mathrm{C}$. These bands were previously assigned to $\mathrm{Rh}^{\mathrm{I}}(\mathrm{CO})_{2}$ (see above). A complex pattern of additional bands between 2100 and $2030 \mathrm{~cm}^{-1}$ is present above $200{ }^{\circ} \mathrm{C}$. Distinct peaks are visible at $2100,2088,2072,2054$ and $2031 \mathrm{~cm}^{-1}$ in the spectra. The $\mathrm{Rh}-\mathrm{Ga}$ phase diagram suggests that at these $\mathrm{Ga} / \mathrm{Rh}$ ratios even heating to $450{ }^{\circ} \mathrm{C}$ may not be sufficient to cross the liquidus curve of the system[38]. In accordance with our microscopic and XPS data we assume that liquid Ga and solid Ga$\mathrm{Rh}$ phases coexist under these conditions. This is in-line with the observation of several well-defined peaks in the spectra pointing to a heterogeneous system with a variety of CO adsorption sites. Due to the complex shape of the spectra, it is not possible to assign each band unequivocally. It is nevertheless clear that the peaks correspond to $\mathrm{Rh}$ on-top species. As they are not observed for the $\mathrm{Rh} / \mathrm{Al}_{2} \mathrm{O}_{3}$ reference sample, we conclude that they are due to $\mathrm{CO}$ adsorbed on-top of $\mathrm{Rh}$ atoms in a Ga environment or at solid Rh-Ga intermetallic phases.

For the $\mathrm{Ga}_{88} / \mathrm{Rh}_{1} / \mathrm{Al}_{2} \mathrm{O}_{3}$ sample, an additional feature at $1974 \mathrm{~cm}^{-1}$ was observed up to $300{ }^{\circ} \mathrm{C}$ that was not found in the other samples with lower Ga to $\mathrm{Rh}$ ratios. We assume that this band originates from a Rh carbonyl species formed at very low Rh loadings only. Frank et al. assigned bands at 1999 and $1954 \mathrm{~cm}^{-1}$ to on-top $\mathrm{CO}$ adsorbates on very small $\mathrm{Rh}$ deposits on $\mathrm{Al}_{2} \mathrm{O}_{3}$. Still, it is fair to say that their studies were conducted in ultra-high vacuum at low temperatures[39]. 


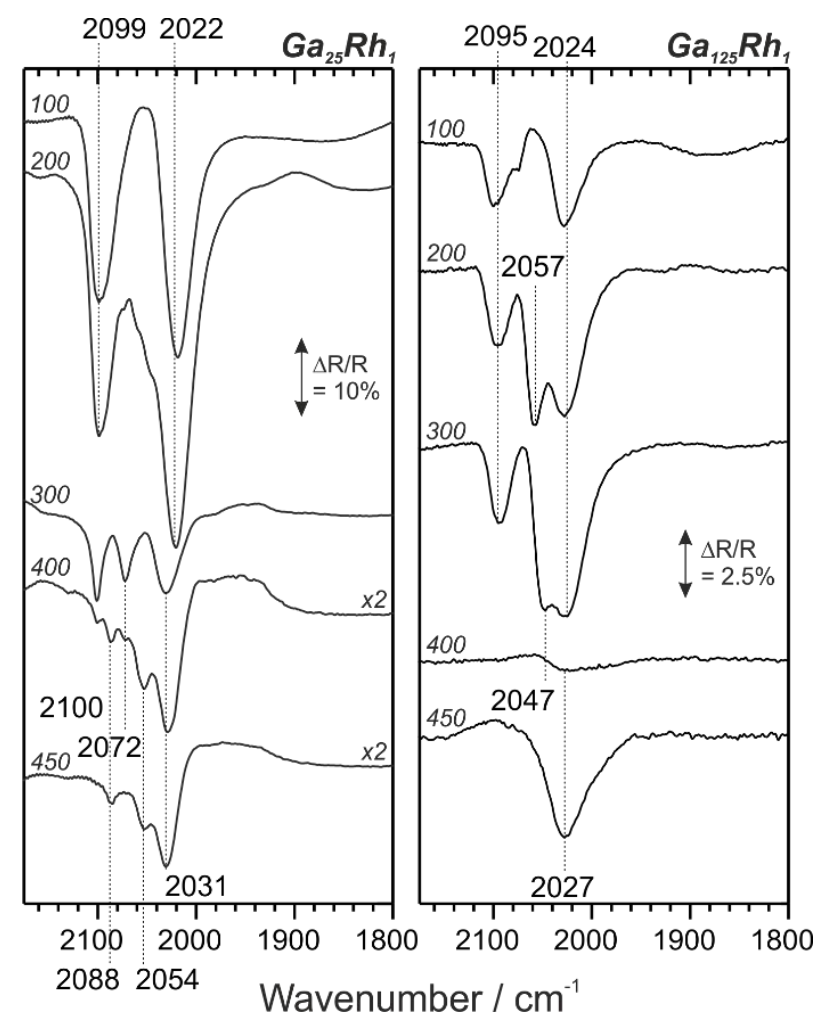

Figure S26: $\mathrm{CO}$ stretching region of the DRIFT spectra obtained from $\mathrm{Ga}_{x}-\mathrm{Rh}_{y} / \mathrm{Al}_{2} \mathrm{O}_{3}$ samples in $\mathrm{Ar}$ atmosphere after treatment with $C O$. The temperature in ${ }^{\circ} \mathrm{C}$ and the scaling factors are indicated on the left and right side of each panel, respectively.

For the $\mathrm{Ga}_{125}-\mathrm{Rh}_{1} / \mathrm{Al}_{2} \mathrm{O}_{3}$ sample, the $\mathrm{Rh}-\mathrm{Ga}$ phase diagram [40] suggests that the system forms a homogeneous and fully liquid phase upon heating to $450{ }^{\circ} \mathrm{C}$. The spectra depicted in Figure S25 show two features at 2095 and $2024 \mathrm{~cm}^{-1}$ which originate from the $\mathrm{Rh}^{\mathrm{I}}(\mathrm{CO})_{2}$ dicarbonyl. At $200{ }^{\circ} \mathrm{C}$ and 300 ${ }^{\circ} \mathrm{C}$, an additional band at $2057 \mathrm{~cm}^{-1}$ is observed which matches the $\mathrm{Rh}^{0}(\mathrm{CO})$ species. At $400{ }^{\circ} \mathrm{C}$, a weak and broad feature is present at $\sim 2027 \mathrm{~cm}^{-1}$, whereas at $450^{\circ} \mathrm{C}$ the band is well-defined. In accordance with data obtained from the $\mathrm{Ga}_{88} \mathrm{Rh}_{1}$ and pure Ga sample we again assign the band at $2027 \mathrm{~cm}^{-1}$ to hydrides on reduced Ga. The sample shows no clear feature below $2000 \mathrm{~cm}^{-1}$. We assume that due to the low amount of $\mathrm{Rh}$ in the sample the intensity of carbonyl features in a liquid Ga matrix is below our detection limit or the peak is covered by the more intense Ga hydride peak at elevated temperatures. 


\section{$\underline{\text { References }}$}

1 Shiver, D.F.; Shirk, A.E. Inorg. Synth. 1977, 17, 42

2 Pantförder, J.; Pöllmann, S.; Zhu, J. F.; Borgmann, D.; Denecke, R.; Steinrück, H.-P. Review of Scientific Instruments 2005, 76, 014102.

3 Yan, Y. L.; Helfand, M. A.; Clayton, C. R. Applied Surface Science 1989, 37, 395.

4 Grabau, M.; Calderon, S. K.; Rietzler, F.; Niedermaier, I.; Taccardi, N.; Wasserscheid, P.; Maier, F.; Steinrück, H.-P.; Papp, C. Surface Science 2016, 16, 651.

5 Contour, J. P.; Mouvier, G.; Hoogewys, M.; Leclere, C. Journal of Catalysis. 1977, 48, 217.

6 Grass, M. E.; Zhang, Y.; Butcher, D. R.; Park, J. Y.; Li, Y.; Bluhm, H.; Bratlie, K. M.; Zhang, T.; Somorjai, G. A. Angewandte Chemie 2008, 120, 9025.

7 Urban, K. W.; Jia, C.-L.; Houben, L.; Lentzen, M.; Mi, S.-B.; Tillmann K. Philosophical transactions. Series A, 2009, 367, 3735 .

8 Boström, M.; Prots Y.; Grin, Y. Journal of Solid State Chemistry, 2006, 179, 2472.

9 Boström, M.; Rosner, H.; Prots, Y.; Burkhardt, U.; Grin, Y. Z. Anorg. Allg. Chem. 2005, 631, 534.

10 Richter, H. Journal of Vacuum Science and Technology, 1969, 6, 855.

11 Niekiel, F.; Kraschewski, S. M.; Müller, J.; Butz B.; Spiecker, E. Ultramicroscopy 2017, 176, 161.

12 Niekiel, F. Master Thesis, Friedrich-Alexander-Universität Erlangen-Nürnberg 2013

13 Richter, H. Journal of Vacuum Science and Technology 1969, 5, 855.

14 Medvedev, N. N.; Naberukhin, Y. I.; Semenova, I. Y. Journal of Non-Crystalline Solids, 1984, 64, 421.

15 Kresse, G.; Furthmüller, J. Comp. Mater. Sci. 1996, 6, 15.

16 Kresse, G.; Furthmüller, J. Phys. Rev. B 1996, 54, 11169.

17 Kresse, G.; Joubert, D. Phys. Rev. B 1999, 59, 1758.

18 Perdew, J. P.; Burke, K.; Ernzerhof, M.; Kresse, G.; Joubert, D. Phys. Rev. Lett. 1996, 77, 3865.

19 Grimme, S.; Antony, J.; Ehrlich, S.; Krieg, H. J. Chem. Phys 2010, 132, 154104.

20 Grabau, M.; Erhard, J.; Taccardi, N.; Calderon, S. K.; Wasserscheid, P.; Görling, A.; Steinrück, H.-P.; Papp, C. Chem. Eur. J. 2017, 23, 17701.

21 Taccardi, N.; Grabau, M.; Debuschewitz, J.; Distaso, M.; Brandl, M.; Hock, R.; Maier, F.; Papp, C.; Erhard, J.; Neiss, C.; Peukert, W.; Görling, A.; Steinrück, H.-P.; Wasserscheid, P. Nat. Chem. 2017, 9, 862.

22 Nosé, S. J. Chem. Phys. 1984, 81, 511.

23 Mermin, N.D. Phys Rev. 1965, 137, A1441.

24 Brehm, M.; Kirchner, B. J. Chem. Inf. Model. 2011, 51, 2007.

25 Thomas, M.; Brehm, M.; Fligg, R.; Voehringer, P.; Kirchner, B. Phys. Chem. Chem. Phys. 2015, 17, 3207.

26 Linke, R.; Curulla, D.; Hopstaken, M. J. P.; Niemantsverdriet, J. W. J. Chem. Phys. 2001, 115, 17.

27 Methfessel, M.; Paxton, A. T. Phys. Rev. B 1989, 40, 3616.

28 Henkelman, G.; Uberuaga, B. P.; Jónsson, H. J. Chem. Phys. 2000, 113, 9901.

29 Henkelman, G.; Jónsson, H. J. Chem. Phys. 1999, 111, 7010.

30 Larsen, A.H.; Mortensen, J.J.; Blomqvist, J.; Castelli, I. E.; Christensen, R.; Dułak, M.; Friis, J.; Groves, M.1 N.; Hammer, B.; Hargus, C.; Hermes, E. D.; Jennings, P. C.; Bjerre Jensen, P.; Kermode, J.; Kitchin, J. R.;

Kolsbjerg, E. L.; Kubal, J.; Kaasbjerg, K.; Lysgaard, S.; Maronsson, J. B.; Maxson, T.; Olsen, T.; Pastewka, L.; Peterson, A.; Rostgaard, C.; Schiøtz, J.; Schütt, O.; Strange, M.; Thygesen, K. S.; Vegge, T.; Vilhelmsen, L.; Walter, M.; Zeng Z.; Jacobsen, K. W. J. Phys.: Condens. Matter. 2017, 29, 273002.

31 Tang, W.; Sanville, E.; Henkelman, G. J. Phys.: Condens. Matter 2009, 21, 084204.

32 Henkelman, G.; Arnaldsson, A.; Jónsson, H. Comput. Mater. Sci. 2006, 36, 354.

33 Bulushev, D. A.; Froment, G. F., J. Mol. Catal. A: Chem. 1999, 139, 63.

34 Solymosi, F.; Knozinger, H. J. Chem. Soc., Faraday Trans. 1990, 86, 389.

35 Trautmann, S.; Baerns, M. J. Catal. 1994, 150, 335.

36 Finocchio, E.; Busca, G.; Forzatti, P.; Groppi, G.; Beretta, A. Langmuir 2007, 23, 10419.

37 Collins, S. E.; Baltanás, M. A.; Garcia Fierro, J. L.; Bonivardi, A. L. J. Catal. 2002, 211, 252.

38 Anres, P.; Gaune-Escard, M.; Bros, J. P. J. Alloys Compd. 1998, 265, 201.

39 Frank, M.; Kühnemuth, R.; Bäumer, M.; Freund, H.-J. Surf. Sci. 2000, 454-456 (Supplement C), 968.

40 Bader, R. W. F. Atoms in Molecules (A Quantum Theory). Oxford University Press: 1991; Vol. 95, p 1308. 